\title{
Re-entrant phase transition of the crystalline ion conductor $\mathrm{Ag}_{7} \mathrm{P}_{3} \mathrm{~S}_{11}$
}

\author{
Christian Brinkmann ${ }^{\mathrm{a}}$, Hellmut Eckert ${ }^{\mathrm{a}, *}$, Dirk Wilmer ${ }^{\mathrm{a}}$, Michael Vogel ${ }^{\mathrm{a}}$, \\ Jörn Schmedt auf der Günne ${ }^{\mathrm{b}}$, Wilfried Hoffbauer ${ }^{\mathrm{b}}$, Franz Rau ${ }^{\mathrm{c}}$, Arno Pfitzner ${ }^{\mathrm{c}, *}$ \\ a Institut für Physikalische Chemie, Westfälische Wilhelms-Universität Münster, Schlossplatz 7, 48149 Münster, Germany \\ b Institut für Anorganische Chemie, Universität Bonn, Gerhard-Domagk-Str. 1, 53121 Bonn, Germany \\ ${ }^{c}$ Institut für Anorganische Chemie, Universitätstraße 31, Universität Regensburg, 93040 Regensburg, Germany
}

Received 30 March 2004; accepted 4 April 2004

Available online 15 September 2004

\begin{abstract}
A highly unusual structural evolution has been observed in temperature dependent studies of the fast ion conductor $\mathrm{Ag}_{7} \mathrm{P}_{3} \mathrm{~S}_{11}$, using $\mathrm{X}$-ray diffraction, Raman scattering, ${ }^{31} \mathrm{P}$ and ${ }^{109} \mathrm{Ag}$ NMR spectroscopy, and electrical conductivity measurements. At $205 \mathrm{~K}$ the high-temperature $\gamma$-phase (space group $C 2 / c$ ) undergoes a phase transition to an intermediate $\beta$-phase of different symmetry. At a temperature near $130 \mathrm{~K}$ another phase transition is observed resulting in the formation of an ordered low-temperature $\alpha$-modification crystallizing in the same space group as the $\gamma$-phase. Restoration of the high-temperature-phase symmetry in the low-temperature phase is unambiguously confirmed by single-crystal X-ray structure determination and ${ }^{31} \mathrm{P}$ solid state NMR peak multiplicities. The re-entrant phase behavior is further supported by temperature dependent electrical conductivity measurements, which reveal that the activation energies of the dc conductivity for the $\alpha$ - and $\gamma$-phases are identical and significantly lower compared to those measured in the $\beta$-phase. Although the $\beta$-to $\gamma$-phase transition is associated with a change in enthalpy, those observables reflecting silver ion dynamics show no discontinuities at the phase transition temperature. The high-temperature $\gamma$-phase crystallizes in the monoclinic system, space group $C 2 / c$ (No. 15), $a=23.999(2) \AA, b=6.3621(3) \AA, c=$ 24.909(2) $\AA, \beta=110.926(7)^{\circ}, R=0.0318$ (300 K). The low-temperature $\alpha$-phase is isostructural with $a=24.090(1) \AA, b=6.3400(3) \AA$, $c=24.581(1) \AA, \beta=110.870(6)^{\circ}, R=0.0317(120 \mathrm{~K})$. Contrary to the situation in $\gamma-\mathrm{Ag}_{7} \mathrm{P}_{3} \mathrm{~S}_{11}$, all the silver atoms are well-localized in the $\alpha$-phase.
\end{abstract}

(c) 2004 Elsevier SAS. All rights reserved.

\section{Introduction}

Re-entrant phenomena are frequently found in liquid crystalline and lyotrophic systems [1-3], whereas they have been rarely observed in the crystalline state [4-7]. Here we are reporting this phenomenon in the crystalline ion conductor $\operatorname{Ag}_{7} \mathrm{P}_{3} \mathrm{~S}_{11}$. As illustrated in detail below, this material undergoes two phase transitions upon cooling from room temperature. Along this course, the symmetry of the high temperature $\gamma$-phase (space group $C 2 / c$ ) decreases upon

\footnotetext{
* Corresponding authors.

E-mail addresses: eckerth@uni-muenster.de (H. Eckert), arno.pfitzner@chemie.uni-regensburg.de (A. Pfitzner).
}

the first phase transition, but is subsequently restored in the second phase transition to the low temperature $\alpha$-phase. To facilitate a satisfactory explanation of this unusual behavior it is essential to characterize in detail all the relevant structural and dynamic aspects associated with this transition. To this end, usage of complementary techniques with different intrinsic time scales and correlation lengths is essential. We present here the results of a comprehensive investigation using differential scanning calorimetry (DSC), single-crystal X-ray diffraction, variable temperature ${ }^{31} \mathrm{P}$ and ${ }^{109} \mathrm{Ag}$ solid state NMR spectroscopies and Raman scattering, as well as electrical conductivity measurements. As will be discussed in the following, these techniques document the critical roles of short range order and local dynamic effects observed during the course of both phase transitions. 


\section{Experimental}

The synthesis of $\mathrm{Ag}_{7} \mathrm{P}_{3} \mathrm{~S}_{11}$ has been described in detail elsewhere [8]. In brief, stoichiometric amounts of silver (Acros, 99.8\%), phosphorus (Aldrich, 99.99\%) and sulfur (Fluka, 99.999\%) were heated in an evacuated silica ampule at $850^{\circ} \mathrm{C}$ for two hours. Subsequently, the temperature was lowered to $550^{\circ} \mathrm{C}$ and the sample kept at this temperature for one day before cooling the furnace to room temperature. Since the title compound is metastable below $574 \mathrm{~K}$ [9] the reaction mixture has to be cooled rapidly to room temperature in order to avoid eutectoidal decomposition. Polycrystalline ${ }^{109} \mathrm{Ag}$ labeled material was synthesized in the same way, using $\mathrm{Ag}$ powder with an isotopic purity of 98\% (Campro Scientific). Single crystals suitable for a structure determination were obtained from stoichiometric reaction mixtures containing a trace of iodine to enhance crystal growth. The identity and purity of the samples were verified by X-ray powder diffraction (X'Pert PW 3040 Philips diffractometer), using a $\mathrm{Cu}-\mathrm{K} \alpha_{1}$ anode and ${ }^{31} \mathrm{P}$ magic-angle spinning (MAS) NMR and Raman spectroscopy. For reproducibility all the measurements were carried out on at least two independent samples. Differential scanning calorimetry was done using a NETZSCH DSC-200 apparatus, using a heating rate of $10 \mathrm{~K} \mathrm{~min}^{-1}$.

$\mathrm{X}$-ray diffraction intensities were collected at different temperatures on a STOE IPDS using Mo-K $\alpha$ radiation. Since the spectroscopic results (see below) give some significant hints for phase transitions in the low temperature regime, X-ray data were also collected at 180 and $120 \mathrm{~K}$. These measurements were performed with an Oxford cryostream cooling device attached to the diffractometer. It allows to control the temperature within a range of $\pm 2 \mathrm{~K}$. The single crystal remained intact throughout two reversible phase transitions observed. The data were corrected for Lorentz and polarization effects. An empirical absorption correction was applied following an optimization of the description of the crystal shape with the X-SHAPE routine. Raman spectroscopic measurements were conducted with a JOBIN YVON HORIBA Raman spectrometer, operating with a diode laser at $785.4 \mathrm{~nm}$. Sample temperature equilibration was found to be complete after $5 \mathrm{~min}$. The precise phase transition temperatures were deduced from abrupt changes observed in the Raman spectra. ${ }^{31} \mathrm{P}$ solid state NMR spectra were recorded at $162.02 \mathrm{MHz}$ on a BRUKER DSX400 spectrometer ( $9.4 \mathrm{~T}$ magnet), in a $4 \mathrm{~mm}$ MAS probe operating at a spinning frequency of $4000 \mathrm{~Hz}$. A flow of nitrogen gas controlled by a BRUKER VT 3000 heating unit was used to adjust the sample temperature; thermocouple readings were calibrated on the transition temperatures determined by the variable temperature Raman spectra and were usually found to be accurate within $5 \mathrm{~K}$. Signals were acquired with $90^{\circ}$ pulses of $4 \mu$ s length using relaxation delays up to $960 \mathrm{~s}$. Chemical shift tensor components were estimated from spinning sideband intensity profiles, using least-squares fitting procedures supplied by the program
DMFIT [10]. Peak assignments were assisted by further 2D INADEQUATE spectra, obtained on a VARIAN Infinity plus spectrometer equipped with a $4 \mathrm{~mm} \mathrm{T3}$ probe upgraded with a low gamma extension box for ${ }^{109} \mathrm{Ag}$ experiments. The pulse spacing for maximizing the ${ }^{31} \mathrm{P}$ double quantum coherence signal was based on an isotropic scalar coupling constant of $23 \mathrm{~Hz}$ [11]. The 2D data set was acquired according to the STATES method [12], using $28 t_{1}$ increments with a repetition time of $30 \mathrm{~s}$. A $35 \mathrm{~ms}$ zero-quantum filter was employed prior to the read-out pulse. DQ coherences were selected by a 4-step phase cycle. Prior to acquiring each data set in $t_{1}$ a stationary value of $z$-magnetization was generated by a saturation comb. Chemical shifts are reported relative to $85 \%$ phosphoric acid. Variable temperature static ${ }^{109} \mathrm{Ag}$ NMR spectra were taken at $23.3 \mathrm{MHz}$ using the BRUKER DSX 500 spectrometer equipped with a $7 \mathrm{~mm}$ MAS probe (operated in the non-spinning mode). For the acquisition of low-temperature spectra a home-built static probe was used in addition. The same equipment was used to measure the spin-lattice relaxation times via the saturation recovery method. Variable temperature ${ }^{109} \mathrm{Ag}$ MAS-NMR spectra were taken at $18.6 \mathrm{MHz}$ on the VARIAN spectrometer, using a spinning rate of $10 \mathrm{kHz}$. The ${ }^{109} \mathrm{Ag} 90^{\circ}$ pulse lengths were typically about 8 and $6.6 \mu$ s in the static and the MAS experiments, respectively, and the relaxation delays were systematically varied. The signal to noise ratio attainable in the $\alpha$ - and $\beta$-phases is severely limited by extremely slow spin-lattice relaxation. Indeed, the ${ }^{109} \mathrm{Ag}$ MAS-NMR spectrum of the $\alpha$-phase could only be obtained by cycling the sample through the $\gamma$-phase at $190 \mathrm{~K}$ (where ${ }^{109} \mathrm{Ag}$ relaxation is fast) each time before co-adding a new scan at $130 \mathrm{~K}$. All chemical shifts are reported relative to a $9 \mathrm{M}$ aqueous $\mathrm{AgNO}_{3}$ solution containing $0.25 \mathrm{M} \mathrm{Fe}(\mathrm{III})$ nitrate as a relaxation enhancer.

AC electrical conductivities were measured within the temperature range $303>T>120 \mathrm{~K}$ on pelletized powders uniaxially pressed at $10 \mathrm{kbar}$ with sputtered silver electrodes. A NOVOCONTROL alpha-S high resolution dielectric analyzer was used, operated at frequencies from $10 \mathrm{mHz}$ to $3 \mathrm{MHz}$. Two independent sets of measurements were conducted at applied voltages of 100 and $200 \mathrm{mV}$. Bulk and grain boundary contributions were separated by complex plane data analysis.

\section{Results and interpretation}

\subsection{Differential Scanning Calorimetry}

Fig. 1 shows a typical DSC thermogram. Upon cooling the onset temperature (defined according to [13]) of the $\gamma-\rightarrow \beta$-phase transition is determined to $198 \mathrm{~K}$, whereas the heating cycle yields an onset temperature of $204 \mathrm{~K}$. The hysteresis effect is a common feature typical for first-order phase transitions. From the area of the DSC peak, the phase transition enthalpy is $360.2 \mathrm{~J} \mathrm{~mol}^{-1}$. It was not possible to 


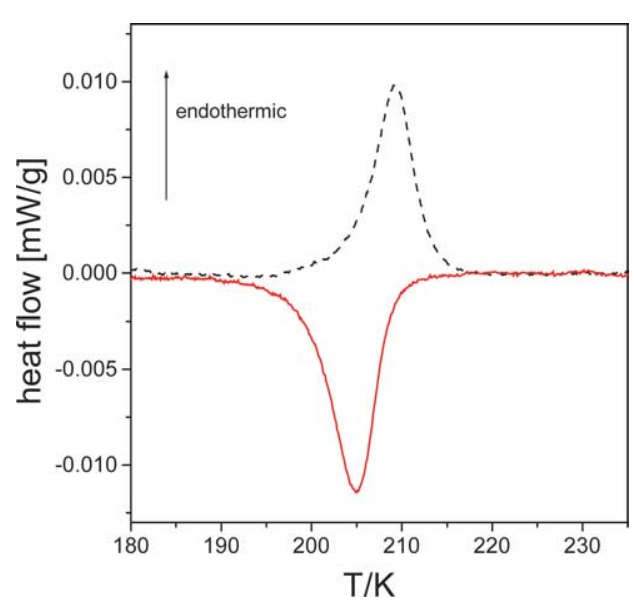

Fig. 1. Differential Scanning Calorimetry of $\mathrm{Ag}_{7} \mathrm{P}_{3} \mathrm{~S}_{11}$, revealing the $\gamma \leftrightarrow \beta$ phase transition. The solid curve was obtained upon cooling, the dashed curve upon heating.

characterize the $\beta$ - to $\alpha$-phase transition by DSC, as the corresponding transition temperature lies outside of the operating range of the Thermal Analyzer available. However, independent evidence of this phase transition was obtained by numerous spectroscopic results, as discussed further below.

\subsection{Single crystal $X$-ray diffraction}

Fig. 2 shows single crystal X-ray diffraction patterns at 298,180 and $120 \mathrm{~K}$. At room temperature a monoclinic cell with $a=23.999$ (2) $\AA, b=6.3621$ (3) $\AA, c=24.909$ (2) $\AA$, $\beta=110.926(7)^{\circ}$ and $V=3552.4(4) \AA^{3}$ was derived from the positions of 8000 reflections. These data are in good agreement with earlier investigations reported by Toffoli et al. [8]. The diffraction patterns at $180 \mathrm{~K}$ suffer from severe broadening and splitting of the reflections and to date the images could not be indexed properly. Nevertheless, a comparison of the images taken at room temperature and at $180 \mathrm{~K}$ shows that there is some relation between the unit cells at both temperatures. In contrast, the diffraction pattern at $120 \mathrm{~K}$ reflects an almost unchanged unit cell as compared to that at room temperature, i.e., $a=24.090(1) \AA$, $b=6.3400(3) \AA, c=24.581(1) \AA, \beta=110.870(6)^{\circ}$ and $V=3508.0(3) \AA^{3}$. It is noteworthy that the broad reflections observed for the $\beta$-phase turn very sharp in the $\alpha$-phase (EMS $=0.005$ for both $T=298 \mathrm{~K}$ and $T=120 \mathrm{~K}$ ). Table 1 collects crystallographic data for $\mathrm{Ag}_{7} \mathrm{P}_{3} \mathrm{~S}_{11}$ at 120 and $298 \mathrm{~K}$ and Table 2 lists the atomic coordinates and isotropic displacement parameters.

The crystal structure of $\boldsymbol{\alpha}-\mathbf{A g}_{7} \mathrm{P}_{\mathbf{3}} \mathbf{S}_{\mathbf{1 1}}$ at $120 \mathrm{~K}$ could be solved straightforwardly by direct methods yielding the positions of seven silver atoms, three phosphorus atoms and eleven sulfur atoms. A conventional anisotropic refinement of the crystal structure in the space group $C 2 / c$ converged to $R=0.0317$. No hints for disorder of the silver atoms were found and all of the positions are fully occupied, suggesting no silver ionic mobility. Table 3 contains the anisotropic dis-
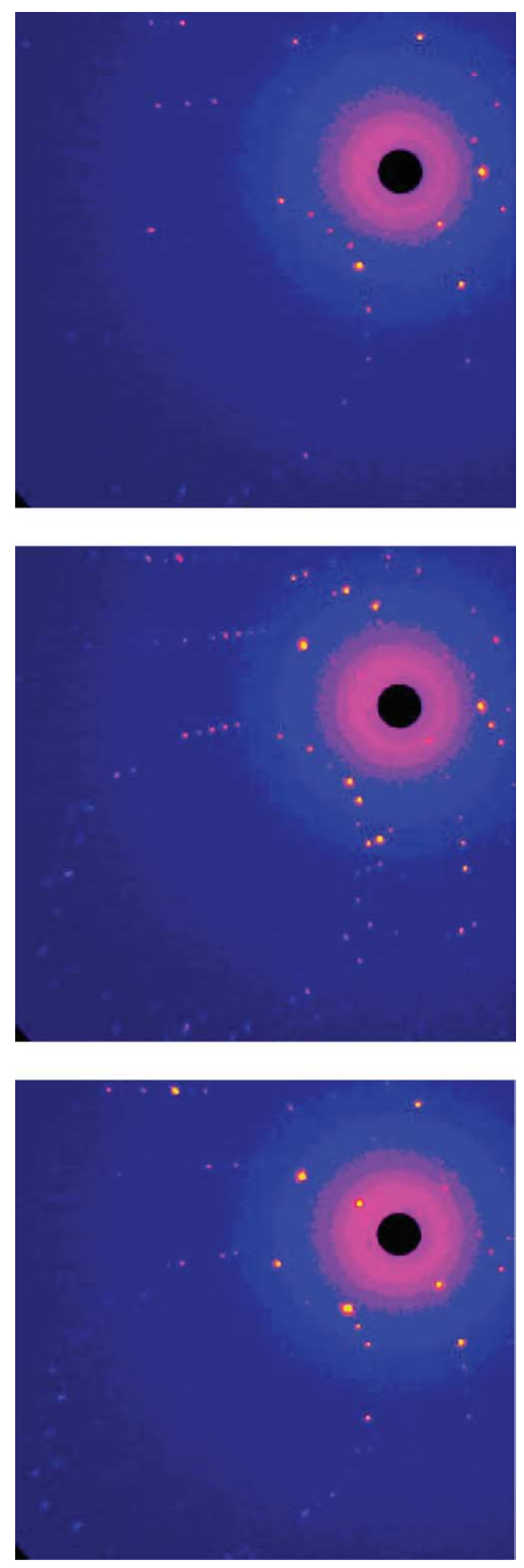

Fig. 2. Temperature dependent evolution of the diffraction patterns of $\mathrm{Ag}_{7} \mathrm{P}_{3} \mathrm{~S}_{11}$. The images were recorded from the same crystal in (arbitrary) identical orientations at $298 \mathrm{~K}$ (top), $180 \mathrm{~K}$ (middle), and at $120 \mathrm{~K}$ (bottom). Note the similarity of the top and bottom patterns. In the middle pattern numerous additional spots are observed and in addition the peaks turn much broader. 
Table 1

Selected crystallographic data of $\mathrm{Ag}_{7} \mathrm{P}_{3} \mathrm{~S}_{11}$ at room temperature and at $120 \mathrm{~K}$

\begin{tabular}{|c|c|c|}
\hline Compound & \multicolumn{2}{|l|}{$\mathrm{Ag}_{7} \mathrm{P}_{3} \mathrm{~S}_{11}$} \\
\hline Formula weight $\left(\mathrm{g} \mathrm{mol}^{-1}\right)$ & \multicolumn{2}{|l|}{1200.66} \\
\hline Color & \multicolumn{2}{|l|}{ Yellow } \\
\hline Crystal shape & \multicolumn{2}{|l|}{ Irregular } \\
\hline Crystal size $\left(\mathrm{mm}^{3}\right)$ & \multicolumn{2}{|l|}{$0.24 \times 0.20 \times 0.08$} \\
\hline Crystal system & \multicolumn{2}{|l|}{ Monoclinic } \\
\hline Space group & \multicolumn{2}{|l|}{$C 2 / c$ (No. 15) } \\
\hline Temperature & $120 \mathrm{~K}$ & $298 \mathrm{~K}$ \\
\hline \multicolumn{3}{|l|}{ Lattice constants $(\AA)$} \\
\hline$a$ & $24.090(1)$ & $23.999(2)$ \\
\hline$b$ & $6.3400(3)$ & $6.3621(3)$ \\
\hline$c$ & 24.581(1) & $24.909(2)$ \\
\hline$\beta$ & $110.870(6)^{\circ}$ & $110.926(7)$ \\
\hline Cell volume $\left(\AA^{3}\right), Z$ & $3508.0(3), 8$ & $3552.4(4), 8$ \\
\hline$\rho_{\mathrm{X} \text {-ray }}\left(\mathrm{g} \mathrm{cm}^{-3}\right)$ & 4.547 & 4.545 \\
\hline$\mu\left(\mathrm{mm}^{-1}\right)$ & 9.214 & 9.214 \\
\hline Diffractometer & \multicolumn{2}{|c|}{$\begin{array}{l}\text { STOE IPDS, Mo-K } \alpha, \\
\lambda=0.71073 \AA \text {, oriented graphite } \\
\text { monochromator }\end{array}$} \\
\hline Image plate distance (mm) & 60 & 55 \\
\hline$\varphi$-range (deg), $\Delta \varphi(\mathrm{deg})$ & $0 \leqslant \varphi \leqslant 180,0.7$ & $0 \leqslant \varphi \leqslant 204,0.8$ \\
\hline $2 \theta$-range $(\mathrm{deg})$ & $3.8<2 \theta<56.3$ & $5.8<2 \theta<58.2$ \\
\hline$h k l$-range & $\begin{array}{l}-31 \leqslant h \leqslant 30 \\
-8 \leqslant k \leqslant 8 \\
-32 \leqslant l \leqslant 32\end{array}$ & $\begin{array}{l}-32 \leqslant h \leqslant 32 \\
-8 \leqslant k \leqslant 8 \\
-32 \leqslant l \leqslant 33\end{array}$ \\
\hline No. of reflections, $R_{\text {int }}$ & $14328,0.0510$ & $18267,0.0327$ \\
\hline No. of independent reflections & 4104 & 4575 \\
\hline No. of parameters & 190 & 330 \\
\hline Refinement program & SHELX-93 [14] & Jana2000 [15] \\
\hline$R(I>n \sigma)$ & $2 \sigma, 0.0317,0.0435$ & $3 \sigma, 0.0318,0.0511$ \\
\hline$w R(I>n \sigma)$ & $2 \sigma, 0.0702,0.0726$ & $3 \sigma, 0.0753,0.0793$ \\
\hline GooF & 0.934 & 1.06 \\
\hline Largest difference peaks & & \\
\hline$\Delta \rho_{\min }, \Delta \rho_{\max }\left(\mathrm{e} \AA^{-3}\right)$ & $-1.42,+2.11$ & $-1.35,+2.05$ \\
\hline
\end{tabular}

placement parameters and Table 4 lists selected distances for the low temperature refinement at $120 \mathrm{~K}$.

No unit cell or even a satisfactory structure model could yet be obtained for $\boldsymbol{\beta}-\mathbf{A g} \mathbf{g}_{\mathbf{7}} \mathbf{P}_{\mathbf{3}} \mathbf{S}_{\mathbf{1 1}}$. Neither was it possible to obtain an unambiguous space group assignment from powder diffraction data. Nevertheless, the change in lattice symmetry (occurring at $205 \mathrm{~K}$ ) and the re-entrant phase behavior (occurring near $130 \mathrm{~K}$ ) are clearly documented by the temperature dependent single crystal diffraction patterns shown in Fig. 2.

The crystal structure of $\boldsymbol{\gamma}-\mathbf{A} \mathbf{g}_{\mathbf{7}} \mathbf{P}_{\mathbf{3}} \mathbf{S}_{\mathbf{1 1}}$ at room temperature was solved by using direct methods within the SHELX program suite [14]. The positions of three phosphorus atoms and eleven sulphur atoms were obtained, and numerous additional peaks were found. These were assigned to silver atoms. However, due to a pronounced disorder of silver only one of these positions seems to be fully occupied. The refinement converged to $R=0.0414$ when a total of 16 disordered silver positions was taken into account. A lot of short distances between these positions resulted in large correlations during the refinement. In addition, the anisotropic displacement parameters were found very large. In order to obtain
Table 2

Atomic coordinates and isotropic displacement parameters in $\AA^{2}$ of $\mathrm{Ag}_{7} \mathrm{P}_{3} \mathrm{~S}_{11}$ at $120 \mathrm{~K}$ and at room temperature (in italics)

\begin{tabular}{|c|c|c|c|c|c|}
\hline Atom & s.o.f. & $x$ & $y$ & $z$ & $U_{\mathrm{eq}}{ }^{\mathrm{a}}$ \\
\hline Ag1 & 1.0 & $0.02268(2)$ & $0.19273(8)$ & $0.18709(2)$ & $0.0175(1)$ \\
\hline Agl & $0.690(4)$ & $0.0281(1)$ & $0.1888(2)$ & $0.1822(1)$ & $0.1029(8)$ \\
\hline$A g l^{\prime}$ & $0.065(4)$ & $-0.0034(7)$ & $0.155(2)$ & $0.2121(6)$ & $0.086(6)$ \\
\hline $\operatorname{Ag} 2$ & 1.0 & $0.09085(2)$ & $0.17660(8)$ & $0.10570(2)$ & $0.0204(1)$ \\
\hline$A g 2$ & $0.754(3)$ & $0.08627(8)$ & $0.1944(2)$ & $0.11265(5)$ & $0.0766(7)$ \\
\hline Ag3 & 1.0 & $0.17119(2)$ & $0.72279(8)$ & $0.18598(2)$ & $0.0186(1)$ \\
\hline Ag3 & 1.0 & $0.17441(3)$ & $0.7126(2)$ & $0.19027(3)$ & $0.0465(2)$ \\
\hline $\mathrm{Ag} 4$ & 1.0 & $0.89005(2)$ & $0.28567(8)$ & $0.09945(2)$ & $0.0209(1)$ \\
\hline Ag4 & $0.894(3)$ & $0.88691(6)$ & $0.2714(4)$ & $0.10355(8)$ & $0.100(1)$ \\
\hline Ag5 & 1.0 & $0.74625(2)$ & $0.69313(8)$ & $0.14530(3)$ & $0.0286(1)$ \\
\hline$A g S$ & $0.898(8)$ & $0.74616(8)$ & $0.6816(3)$ & $0.15366(9)$ & $0.1115(9)$ \\
\hline Ag6 & 1.0 & $0.75976(2)$ & $0.05691(9)$ & $0.06678(2)$ & $0.0211(1)$ \\
\hline Ag6 & $0.942(3)$ & $0.76042(5)$ & $0.0360(5)$ & $0.07415(8)$ & $0.115(1)$ \\
\hline $\operatorname{Ag} 7$ & 1.0 & $0.09063(2)$ & $0.73635(9)$ & $0.31800(2)$ & $0.0239(1)$ \\
\hline$A g 7$ & 1.0 & $0.09169(6)$ & $0.7174(3)$ & $0.31353(9)$ & $0.0883(6)$ \\
\hline$A g 8$ & $0.758(3)$ & $0.09009(5)$ & $0.6344(2)$ & $0.01252(4)$ & $0.0569(6)$ \\
\hline P1 & & $0.01055(6)$ & $0.7000(2)$ & $0.10509(6)$ & $0.0076(3)$ \\
\hline$P 1$ & & $0.00754(4)$ & $0.7145(2)$ & $0.10624(4)$ & $0.0158(3)$ \\
\hline $\mathrm{P} 2$ & & $-0.14188(6)$ & $0.8133(2)$ & $0.01736(6)$ & $0.0075(3)$ \\
\hline$P 2$ & & $-0.14295(4)$ & $0.8253(2)$ & $0.01669(4)$ & $0.0160(3)$ \\
\hline P3 & & $0.16718(6)$ & $0.2071(2)$ & $0.27950(6)$ & $0.0075(3)$ \\
\hline P3 & & $0.16631(4)$ & $0.2035(2)$ & $0.28029(4)$ & $0.0149(3)$ \\
\hline S1 & & $-0.04954(6)$ & $0.8834(2)$ & $0.03761(6)$ & $0.0109(3)$ \\
\hline$S 1$ & & $-0.04995(5)$ & $0.8956(2)$ & $0.03776(5)$ & $0.0276(4)$ \\
\hline $\mathrm{S} 2$ & & $0.01170(6)$ & $0.7912(2)$ & $0.18488(6)$ & $0.0106(3)$ \\
\hline$S 2$ & & $0.00644(6)$ & $0.8054(3)$ & $0.18314(5)$ & $0.0375(5)$ \\
\hline S3 & & $0.08485(6)$ & $0.7817(2)$ & $0.08940(6)$ & $0.0114(3)$ \\
\hline S3 & & $0.08508(5)$ & $0.8083(2)$ & $0.09807(5)$ & $0.0272(4)$ \\
\hline S4 & & $-0.00792(6)$ & $0.3860(2)$ & $0.08843(6)$ & $0.0118(3)$ \\
\hline S4 & & $-0.01023(5)$ & $0.4027(2)$ & $0.08834(6)$ & $0.0299(4)$ \\
\hline S5 & & $-0.16555(6)$ & $0.6559(2)$ & $0.07666(6)$ & $0.0115(3)$ \\
\hline S5 & & $-0.16555(6)$ & $0.6610(2)$ & $0.07394(5)$ & $0.0337(5)$ \\
\hline S6 & & $-0.17607(6)$ & $0.1114(2)$ & $0.00526(6)$ & $0.0131(3)$ \\
\hline S6 & & $-0.17854(6)$ & $0.1190(2)$ & $0.00635(6)$ & $0.0344(5)$ \\
\hline S7 & & $-0.16262(6)$ & $0.6420(2)$ & $-0.05788(6)$ & $0.0104(3)$ \\
\hline S7 & & $-0.16293(5)$ & $0.6674(2)$ & $-0.05933(5)$ & $0.0263(4)$ \\
\hline S8 & & $0.17075(6)$ & $0.3182(2)$ & $0.20348(6)$ & $0.0136(3)$ \\
\hline S8 & & $0.16813(7)$ & $0.3124(2)$ & $0.20417(5)$ & $0.0359(5)$ \\
\hline S9 & & $0.24072(6)$ & $0.3002(2)$ & $0.34915(6)$ & $0.0099(3)$ \\
\hline$S 9$ & & $0.24048(5)$ & $0.2986(2)$ & $0.34801(5)$ & $0.0237(4)$ \\
\hline $\mathrm{S} 10$ & & $0.09036(6)$ & $0.3145(2)$ & $0.28954(6)$ & $0.0106(3)$ \\
\hline$S 10$ & & $0.08976(5)$ & $0.3018(2)$ & $0.29053(6)$ & $0.0298(4)$ \\
\hline S11 & & $0.16641(6)$ & $-0.1191(2)$ & $0.27851(6)$ & $0.0104(3)$ \\
\hline$S 11$ & & $0.16653(5)$ & $-0.1201(2)$ & $0.27959(5)$ & $0.0248(4)$ \\
\hline
\end{tabular}

${ }^{\text {a }} U_{\text {eq }}$ is defined as one-third of the trace of the orthogonalized $U_{i j}$ tensor.

a less disordered structural model for the room temperature phase of $\mathrm{Ag}_{7} \mathrm{P}_{3} \mathrm{~S}_{11}$ we started the refinement of the structure by using the atomic positions of the low temperature phase and allowed the silver positions to be not fully occupied. A strong peak in a difference Fourier calculation showed at least one additional silver position. This is denominated Ag8. By using a nonharmonic approach it was possible to 
Table 3

Anisotropic displacement parameters $U_{i}$ (in $\AA^{2}$ ) for $\operatorname{Ag}_{7} \mathrm{P}_{3} \mathrm{~S}_{11}$ at $120 \mathrm{~K}$

\begin{tabular}{llllrrr}
\hline & $U_{11}$ & $U_{22}$ & $U_{33}$ & \multicolumn{1}{c}{$U_{23}$} & \multicolumn{1}{c}{$U_{13}$} & \multicolumn{1}{c}{$U_{12}$} \\
\hline Ag1 & $0.021(1)$ & $0.015(1)$ & $0.015(1)$ & $-0.001(1)$ & $0.003(1)$ & $0.001(1)$ \\
Ag2 & $0.023(1)$ & $0.014(1)$ & $0.030(1)$ & $-0.003(1)$ & $0.016(1)$ & $-0.004(1)$ \\
Ag3 & $0.017(1)$ & $0.023(1)$ & $0.016(1)$ & $-0.004(1)$ & $0.006(1)$ & $0.001(1)$ \\
Ag4 & $0.021(1)$ & $0.020(1)$ & $0.023(1)$ & $-0.007(1)$ & $0.009(1)$ & $-0.001(1)$ \\
Ag5 & $0.025(1)$ & $0.011(1)$ & $0.035(1)$ & $-0.003(1)$ & $-0.008(1)$ & $0.003(1)$ \\
Ag6 & $0.019(1)$ & $0.028(1)$ & $0.021(1)$ & $-0.006(1)$ & $0.012(1)$ & $-0.005(1)$ \\
Ag7 & $0.015(1)$ & $0.034(1)$ & $0.026(1)$ & $0.013(1)$ & $0.011(1)$ & $0.002(1)$ \\
P1 & $0.010(1)$ & $0.006(1)$ & $0.008(1)$ & $0.002(1)$ & $0.003(1)$ & $0.000(1)$ \\
P2 & $0.009(1)$ & $0.007(1)$ & $0.008(1)$ & $0.000(1)$ & $0.004(1)$ & $0.000(1)$ \\
P3 & $0.008(1)$ & $0.007(1)$ & $0.008(1)$ & $0.001(1)$ & $0.004(1)$ & $0.000(1)$ \\
S1 & $0.010(1)$ & $0.011(1)$ & $0.011(1)$ & $0.003(1)$ & $0.002(1)$ & $-0.001(1)$ \\
S2 & $0.012(1)$ & $0.012(1)$ & $0.008(1)$ & $-0.001(1)$ & $0.003(1)$ & $-0.002(1)$ \\
S3 & $0.010(1)$ & $0.011(1)$ & $0.015(1)$ & $0.001(1)$ & $0.006(1)$ & $0.000(1)$ \\
S4 & $0.012(1)$ & $0.007(1)$ & $0.016(1)$ & $-0.001(1)$ & $0.005(1)$ & $-0.001(1)$ \\
S5 & $0.013(1)$ & $0.012(1)$ & $0.011(1)$ & $0.002(1)$ & $0.006(1)$ & $0.000(1)$ \\
S6 & $0.015(1)$ & $0.008(1)$ & $0.016(1)$ & $0.001(1)$ & $0.006(1)$ & $0.003(1)$ \\
S7 & $0.012(1)$ & $0.010(1)$ & $0.009(1)$ & $-0.003(1)$ & $0.004(1)$ & $-0.001(1)$ \\
S8 & $0.018(1)$ & $0.014(1)$ & $0.010(1)$ & $0.001(1)$ & $0.006(1)$ & $-0.003(1)$ \\
S9 & $0.010(1)$ & $0.008(1)$ & $0.010(1)$ & $0.000(1)$ & $0.002(1)$ & $-0.001(1)$ \\
S10 & $0.009(1)$ & $0.012(1)$ & $0.012(1)$ & $-0.002(1)$ & $0.005(1)$ & $0.002(1)$ \\
S11 & $0.013(1)$ & $0.007(1)$ & $0.012(1)$ & $-0.001(1)$ & $0.005(1)$ & $-0.001(1)$ \\
\hline & & & & & &
\end{tabular}
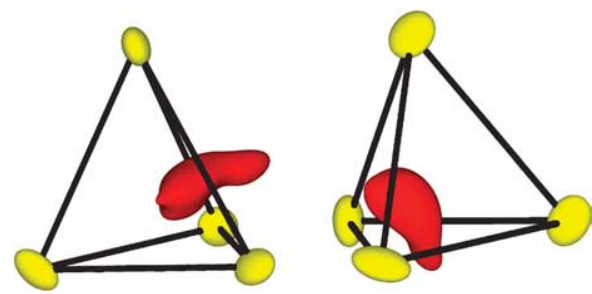

Fig. 3. 3D isosurface of the jpdf of Ag1 (left) and Ag7 (right) in the crystal structure of $\gamma-\mathrm{Ag}_{7} \mathrm{P}_{3} \mathrm{~S}_{11}$ at a level of $90 \%$ probability density both for silver and the surrounding sulfur atoms. The tendency of silver to leave the tetrahedral centers becomes obvious immediately.

refine the room temperature data with these eight silver positions. The silver atoms $\mathrm{Ag} 1-\mathrm{Ag} 8$ were refined with nonharmonic parameters up to the fourth order with the Jana2000 program package [15]. Parameters which took values less than $3 \sigma$ were fixed to zero and were no longer refined in order to minimize the number of parameters. A detailed description of the refinement strategy using a nonharmonic approach is given elsewhere [16]. After the refinement converged only one significant peak was to be regarded as a split position. This is the atom $\mathrm{Ag} 1^{\prime}$. Since the composition of the crystal was known from the refinement of the $120 \mathrm{~K}$ data the sum of all silver occupancies was defined to sum up to seven in the last refinement cycles. From the structural data as collected in Table 2 it becomes obvious that still two silver positions can be regarded as fully occupied (Ag3 and $\mathrm{Ag} 7$ ), and the other positions found at $120 \mathrm{~K}$ are occupied to $75 \%$ or more. The "missing" silver atoms are located at the position of Ag8. From an inspection of the three-dimensional joint probability density function (jpdf) of all silver positions it becomes obvious that the silver atoms tend to become mobile with increasing temperature. Fig. 3 shows the jpdf of the
Table 4

Selected interatomic distances (in $\AA$ ) and angles (in degrees) for $\operatorname{Ag}_{7} \mathrm{P}_{3} \mathrm{~S}_{11}$ at $120 \mathrm{~K}$ with e.s.d.s. given in brackets. For the distances $d(\mathrm{Ag}-\mathrm{S})$ a cutoff of $3 \AA$ is applied

\begin{tabular}{|c|c|c|c|}
\hline Ag1-S2 & $2.558(2)$ & $\mathrm{P} 1-\mathrm{S} 3$ & $2.028(2)$ \\
\hline Ag1-S4 & $2.579(2)$ & $\mathrm{P} 1-\mathrm{S} 2$ & $2.036(2)$ \\
\hline Ag1-S10 & $2.583(1)$ & $\mathrm{P} 1-\mathrm{S} 4$ & $2.049(2)$ \\
\hline Ag2-S3 & $2.532(2)$ & $\mathrm{P} 1-\mathrm{S} 1$ & $2.119(2)$ \\
\hline $\mathrm{Ag} 2-\mathrm{S} 4$ & $2.624(2)$ & P2-S5 & $2.010(2)$ \\
\hline Ag2-S8 & $2.644(2)$ & P2-S6 & $2.041(2)$ \\
\hline Ag2-S7 & $2.673(1)$ & P2-S7 & $2.047(2)$ \\
\hline Ag3-S11 & $2.525(1)$ & P2-S1 & $2.146(2)$ \\
\hline Ag3-S3 & $2.566(2)$ & P3-S8 & $2.027(2)$ \\
\hline Ag3-S8 & $2.602(2)$ & P3-S9 & $2.063(2)$ \\
\hline Ag3-S9 & $2.607(1)$ & P3-S10 & $2.068(2)$ \\
\hline Ag4-S6 & $2.548(2)$ & P3-S11 & $2.068(2)$ \\
\hline Ag4-S10 & $2.605(2)$ & & \\
\hline Ag4-S4 & $2.645(1)$ & S3-P1-S2 & 113.61(9) \\
\hline Ag4-S5 & $2.661(2)$ & S3-P1-S4 & $110.72(8)$ \\
\hline Ag5-S9 & $2.509(2)$ & S2-P1-S4 & 113.33(9) \\
\hline Ag5-S7 & $2.586(2)$ & S3-P1-S1 & $96.54(8)$ \\
\hline Ag5-S8 & $2.799(2)$ & S2-P1-S1 & 111.67(8) \\
\hline Ag5-S11 & $2.558(2)$ & S4-P1-S1 & $109.75(8)$ \\
\hline Ag6-S6 & $2.542(2)$ & & \\
\hline Ag6-S9 & $2.582(2)$ & S5-P2-S6 & $111.19(8)$ \\
\hline Ag6-S7 & $2.598(1)$ & S5-P2-S7 & $110.54(9)$ \\
\hline Ag7-S2 & $2.466(1)$ & S6-P2-S7 & 113.82(9) \\
\hline Ag7-S11 & $2.525(1)$ & S5-P2-S1 & $118.24(9)$ \\
\hline Ag7-S5 & $2.625(2)$ & S6-P2-S1 & $99.96(8)$ \\
\hline Ag7-S10 & $2.764(2)$ & S7-P2-S1 & $102.64(8)$ \\
\hline $\operatorname{Ag} 1-\mathrm{Ag} 2$ & $3.0087(7)$ & S8-P3-S9 & $111.09(8)$ \\
\hline $\mathrm{Ag} 1-\mathrm{Ag} 4$ & $3.2081(7)$ & S8-P3-S10 & $109.23(8)$ \\
\hline Ag4-Ag1 & $3.2081(7)$ & S9-P3-S10 & $110.31(8)$ \\
\hline Ag4-Ag6 & $3.2869(7)$ & S8-P3-S11 & $109.86(9)$ \\
\hline Ag5-Ag6 & $3.0981(8)$ & S9-P3-S11 & $107.29(8)$ \\
\hline Ag6-Ag5 & $3.0981(8)$ & S10-P3-S11 & $109.03(8)$ \\
\hline \multirow{7}{*}{\multicolumn{2}{|c|}{$\begin{aligned} 110 & <\mathrm{S}-\mathrm{Ag} 1-\mathrm{S}<130 \\
83 & <\mathrm{S}-\mathrm{Ag} 2-\mathrm{S}<119 \\
99 & <\mathrm{S}-\mathrm{Ag} 3-\mathrm{S}<120 \\
93 & <\mathrm{S}-\mathrm{Ag} 4-\mathrm{S}<144 \\
82 & <\mathrm{S}-\mathrm{Ag} 5-\mathrm{S}<128 \\
96 & <\mathrm{S}-\mathrm{Ag} 6-\mathrm{S}<138 \\
90 & <\mathrm{S}-\mathrm{Ag} 7-\mathrm{S}<142\end{aligned}$}} & $\mathrm{P} 1-\mathrm{S} 1-\mathrm{P} 2$ & $115.49(8)$ \\
\hline & & & \\
\hline & & & \\
\hline & & & \\
\hline & & & \\
\hline & & & \\
\hline & & & \\
\hline
\end{tabular}

$\mathrm{Ag} 1$ and of the $\mathrm{Ag} 7$ positions at room temperature as an example for this finding. The non-harmonic refinement leads to a better understanding of the crystal structure and in addition the number of silver positions is drastically reduced as compared to a conventional harmonic refinement including numerous split positions. Tables of the nonharmonic displacement parameters are available as supplementary material. The slightly increased number of free parameters yields a much lower $R$ value due to a much better description of the electron density in the unit cell. Therefore, this treatment of the data can be regarded as significant.

Fig. 4 gives a comparison of the crystal structures of $\alpha$ $\mathrm{Ag}_{7} \mathrm{P}_{3} \mathrm{~S}_{11}$ and of $\gamma-\mathrm{Ag}_{7} \mathrm{P}_{3} \mathrm{~S}_{11}$. While the anionic substructure consisting of $\mathrm{PS}_{4}{ }^{3-}$ and $\mathrm{P}_{2} \mathrm{~S}_{7}{ }^{4-}$ units remains the same, the main difference concerns the silver distribution and coordination. Compared to the $\alpha$-phase, the average Ag coordi- 


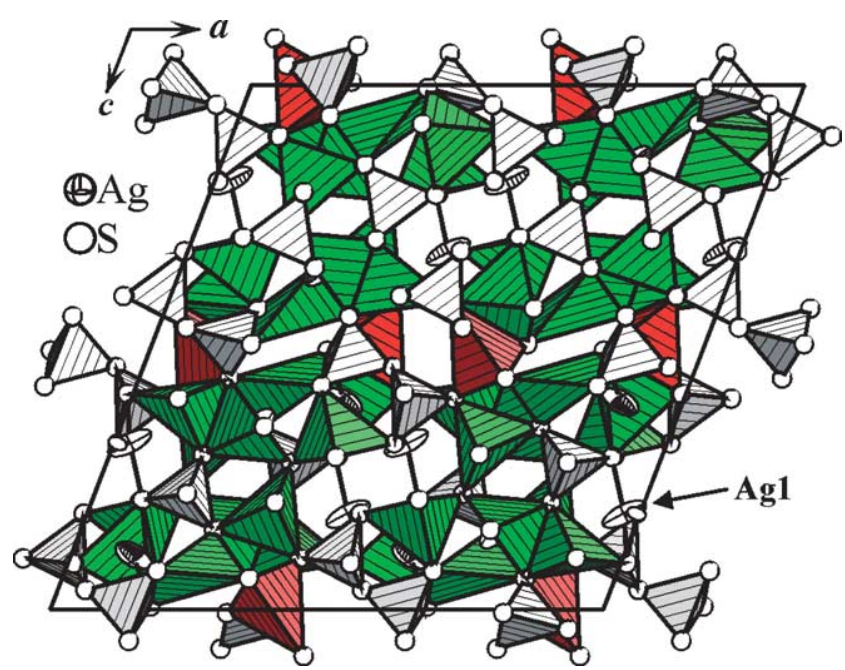

(a)

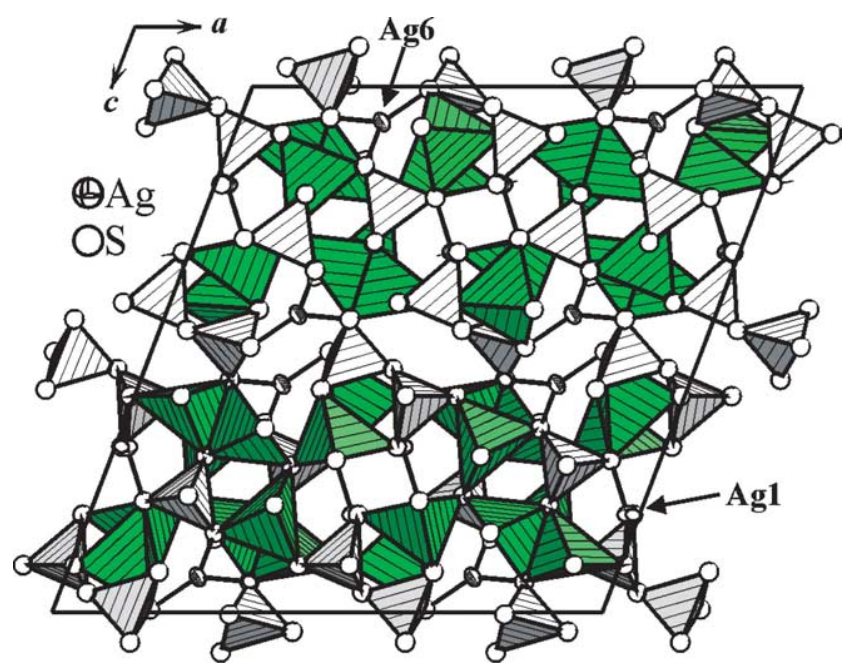

(b)

Fig. 4. Crystal structure of (a) $\gamma-\mathrm{Ag}_{7} \mathrm{P}_{3} \mathrm{~S}_{11}$ and of (b) $\alpha-\mathrm{Ag}_{7} \mathrm{P}_{3} \mathrm{~S}_{11}$. Phosphorus is located within the gray tetrahedra. Green polyhedra are drawn for silver atoms with a coordination of four sulfur atoms within a sphere of $3 \AA$ A. At low temperatures Ag1 and Ag6 show a threefold coordination. Red tetrahedra show the position of Ag8.

nation number in the $\gamma$-phase is slightly increased owing to an increased number of four-coordinate silver atoms. This is in good agreement with findings concerning other $\mathrm{Cu}(\mathrm{I})$ and $\mathrm{Ag}(\mathrm{I})$ compounds [17-19]. Only the positions of Ag3 and Ag7 remain fully occupied at room temperature whereas all the other silver positions show some reduced occupancies. In this context it is noteworthy that $\mathrm{Ag} 3$ and $\mathrm{Ag} 7$ are the only silver sites that do not have any other silver atoms in the neighborhood within a critical radius of $3.3 \AA$, see Fig. 5 .

\subsection{Raman spectroscopy}

Fig. 6 shows the Raman spectra of $\mathrm{Ag}_{7} \mathrm{P}_{3} \mathrm{~S}_{11}$. To facilitate the assignments of the two dominant bands observed near 390 and $410 \mathrm{~cm}^{-1}$, spectra of the model compounds $\mathrm{Ag}_{7} \mathrm{PS}_{6}$ $\left(\mathrm{PS}_{4}{ }^{3-}\right.$ group) and $\mathrm{Ag}_{4} \mathrm{P}_{2} \mathrm{~S}_{7}\left(\mathrm{P}_{2} \mathrm{~S}_{7}{ }^{4-}\right.$ group) are included.

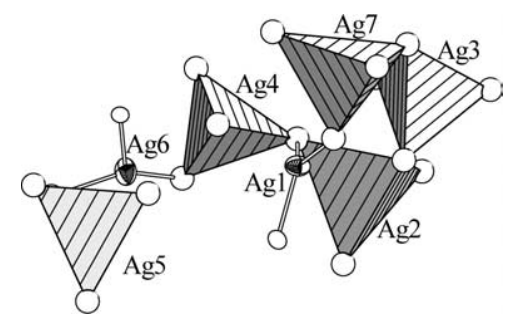

Fig. 5. Arrangement of three- and four-coordinate silver atoms in $\alpha-\mathrm{Ag}_{7}$ $\mathrm{P}_{3} \mathrm{~S}_{11}$. Distances $d(\mathrm{Ag}-\mathrm{Ag})<3.3 \AA$ are found for $\mathrm{Ag} 1, \mathrm{Ag} 2, \mathrm{Ag} 4, \mathrm{Ag} 5$ and Ag6 whereas $\mathrm{Ag} 3$ and $\mathrm{Ag} 7$ do not have any silver atoms as neighbors within this sphere. This might lead to an decreasing occupation of Ag1, $\mathrm{Ag} 2, \mathrm{Ag} 4, \mathrm{Ag} 5$ and Ag6 when the silver mobility increases with temperature.

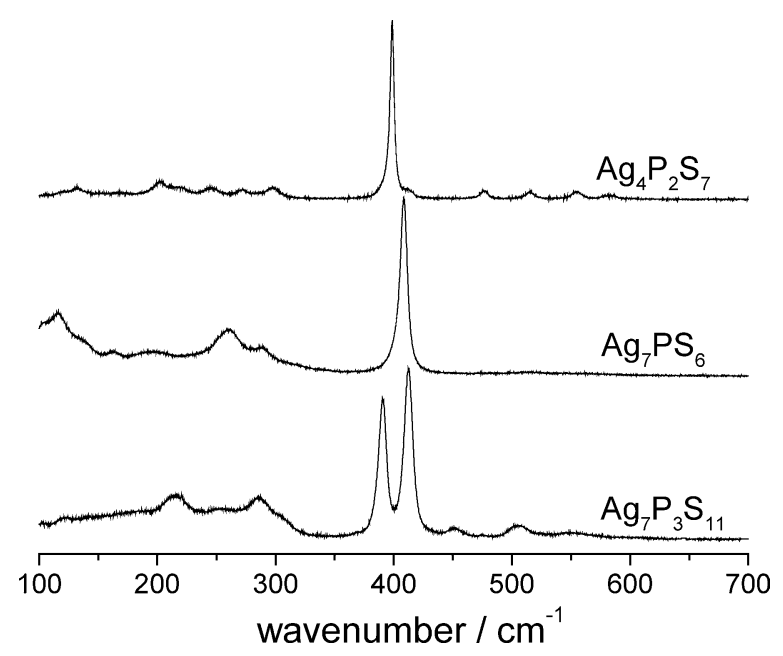

Fig. 6. Raman spectrum of $\gamma-\mathrm{Ag}_{7} \mathrm{P}_{3} \mathrm{~S}_{11}$. For peak assignments, spectra of the model compounds $\mathrm{Ag}_{4} \mathrm{P}_{2} \mathrm{~S}_{7}\left(\mathrm{P}_{2} \mathrm{~S}_{7}{ }^{4-}\right.$ unit) and $\mathrm{Ag}_{7} \mathrm{PS}_{6}\left(\mathrm{PS}_{4}{ }^{3-}\right.$ unit) are included. All the spectra were measured at room temperature.

Table 5

Wave numbers, intensities, and tentative mode assignments of the Raman scattering bands in $\mathrm{Ag}_{7} \mathrm{P}_{3} \mathrm{~S}_{11}$ at $298 \mathrm{~K}$. The nomenclature is that of Ref. [22]

\begin{tabular}{llll}
\hline$\tilde{v}(\mathrm{~cm})$ & Int. & Assign. & \\
\hline 119 & $\mathrm{w}$ & & \\
215 & $\mathrm{~m}$ & & \\
254 & $\mathrm{w}$ & $v_{9}\left(\mathrm{~A}_{2}\right)+v_{2}(\mathrm{E})$ & $\mathrm{P}_{2} \mathrm{~S}_{7}^{4-}+\mathrm{PS}_{4}{ }^{3-}$ \\
285 & $\mathrm{~m}$ & $v_{4}\left(\mathrm{~T}_{2}\right)$ & $\mathrm{PS}_{4}{ }^{3-}$ \\
388 & $\mathrm{vs}$ & $v_{3}\left(\mathrm{~A}_{1}\right)$ & $\mathrm{P}_{2} \mathrm{~S}_{7}{ }^{4-}$ \\
410 & $\mathrm{vs}$ & $v_{1}\left(\mathrm{~A}_{1}\right)$ & $\mathrm{PS}_{4}{ }^{3-}\left(+\mathrm{P}_{2} \mathrm{~S}_{7}{ }^{4-}\right)$ \\
453 & $\mathrm{~m}$ & & \\
476 & $\mathrm{~m}$ & $v_{17}\left(\mathrm{~B}_{2}\right)$ & $\mathrm{P}_{2} \mathrm{~S}_{7}{ }^{4-}$ \\
505 & $\mathrm{w}$ & $v_{2}\left(\mathrm{~A}_{1}\right)+v_{3}\left(\mathrm{~T}_{2}\right)$ & $\mathrm{P}_{2} \mathrm{~S}_{7}{ }^{4-}+\mathrm{PS}_{4}{ }^{3-}$ \\
551 & $\mathrm{~m}$ & $v_{2}\left(\mathrm{~A}_{1}\right)$ & \\
\hline
\end{tabular}

Table 5 summarizes the peak assignments, which are based on previous theoretical and experimental work on related compounds [20-23]. The peak at $390 \mathrm{~cm}^{-1}$ is dominated by the symmetric stretching mode of the $\mathrm{P}_{2} \mathrm{~S}_{7}{ }^{4-}$ unit, whereas the band at $410 \mathrm{~cm}^{-1}$ mainly represents the stretching mode of the $\mathrm{PS}_{4}{ }^{3-}$ group, but likely also includes a minor contri- 


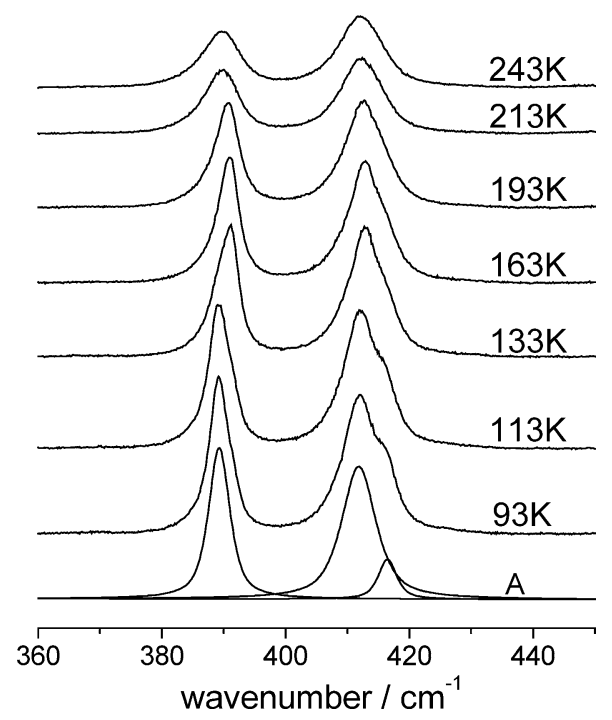

(a)

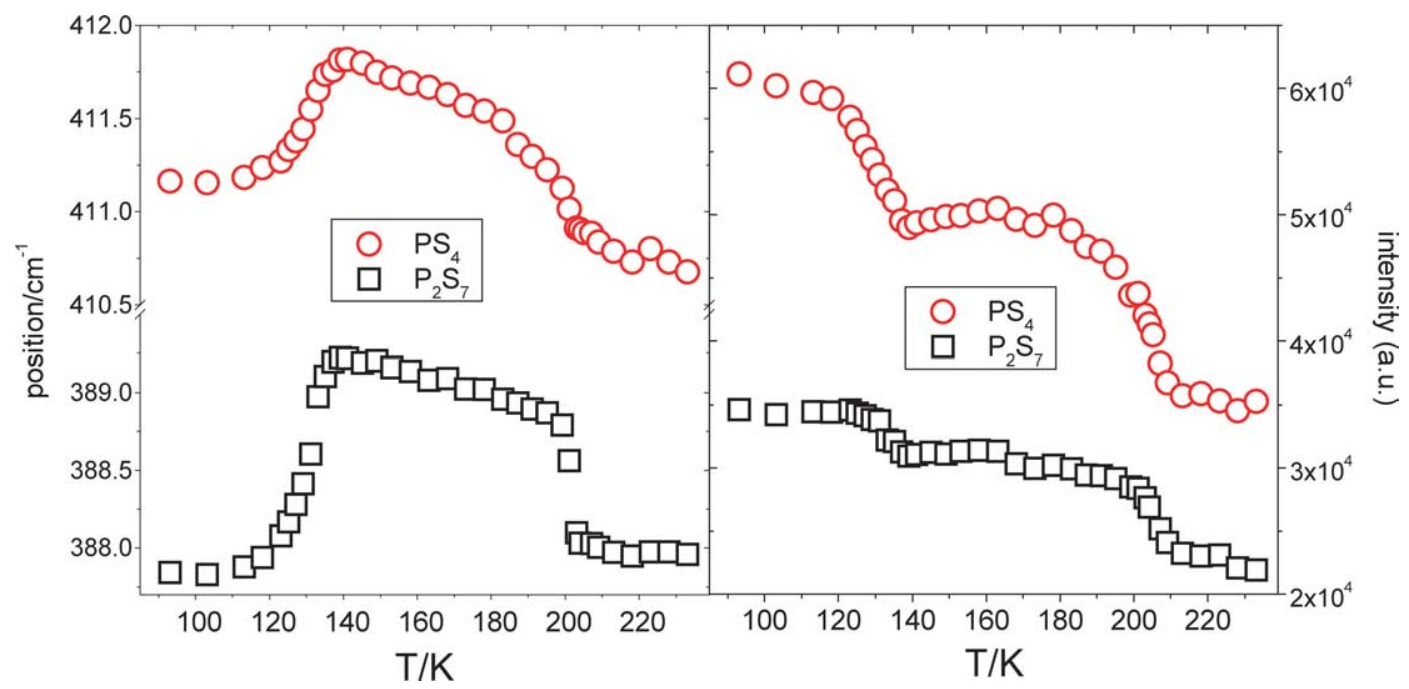

(b)

Fig. 7. (a) Raman spectra of $\mathrm{Ag}_{7} \mathrm{P}_{3} \mathrm{~S}_{11}$ at different temperatures. Trace A shows the deconvolution used in the analysis of the band near $410 \mathrm{~cm}^{-1}$. (b) Temperature dependences of the precise wavenumbers (left) and the peak intensities (right) of the Raman scattering bands near $390 \mathrm{~cm}^{-1}\left(\mathrm{P}_{2} \mathrm{~S}_{7}^{4-}\right.$ unit) and $410 \mathrm{~cm}^{-1}\left(\mathrm{PS}_{4}{ }^{3-}\right.$ unit).

bution from modes of the $\mathrm{P}_{2} \mathrm{~S}_{7}{ }^{4-}$ unit. To locate the precise wavenumbers of these peaks, the bands were fitted to three Lorentz-Gaussian components (see Fig. 7a). As shown in Fig. $7 \mathrm{~b}$, the position and intensities of these hard modes respond sensitively to the structural changes associated with the two phase transitions. In particular, the temperature evolution of the band positions is remarkable. Consistent with the re-entrant phase behavior, the band position for each mode is essentially the same in the $\alpha$ - and the $\gamma$-phases, whereas substantial frequency shifts are observed both near the $\gamma$ - to $\beta$ - and the $\beta$ - to $\alpha$-phase transition temperatures. These shifts clearly indicate that the local structural environments of the thiophosphate moieties change significantly at each phase transition. Note, however, that these changes in Raman frequency do not occur abruptly but are rather distributed over a certain temperature range.

\subsection{High-resolution ${ }^{31} \mathrm{P}$ solid state NMR}

Fig. 8 displays temperature dependent ${ }^{31} \mathrm{P}$ MAS-NMR spectra within the temperature range $300>T>119 \mathrm{~K}$. Isotropic chemical shifts measured from the MAS centerband location and chemical shift anisotropies extracted from the MAS sideband intensity profiles are summarized in Table 6 for selected temperatures. At room temperature the spectrum of $\gamma-\mathrm{Ag}_{7} \mathrm{P}_{3} \mathrm{~S}_{11}$ consists of three resonances centered at 103.0, 101.2 and 91.8 ppm [24]. Based on twodimensional NMR experiments sensitive to homonuclear ${ }^{31} \mathrm{P}-{ }^{31} \mathrm{P}$ dipole-dipole interactions, the resonances at 101.2 and $91.8 \mathrm{ppm}$ can be assigned to the crystallographically inequivalent $\mathrm{P}$ atoms of the $\mathrm{P}_{2} \mathrm{~S}_{7}{ }^{4-}$ group, while the signal at $103.0 \mathrm{ppm}$ is assigned to the $\mathrm{PS}_{4}{ }^{3-}$ group $[25,26]$. This assignment is confirmed further by the fact that the chemical 
Table 6

${ }^{31} \mathrm{P}$ and ${ }^{109} \mathrm{Ag}$ chemical shift parameters in the three polymorphs of $\mathrm{Ag}_{7} \mathrm{P}_{3} \mathrm{~S}_{11}$

\begin{tabular}{|c|c|c|c|c|c|c|c|c|c|c|c|c|c|}
\hline \multirow[t]{2}{*}{${ }^{31} \mathrm{P}(\mathrm{ppm})$} & \multicolumn{3}{|c|}{$\alpha$-phase (119 K) } & \multicolumn{7}{|c|}{$\beta$-phase $(181 \mathrm{~K})$} & \multicolumn{3}{|c|}{$\gamma$-phase $(300 \mathrm{~K})$} \\
\hline & $\mathrm{P}_{2} \mathrm{~S}_{7}^{4-}$ & $\mathrm{PS}_{4}{ }^{3-}$ & $\mathrm{P}_{2} \mathrm{~S}_{7}^{4-}$ & $\mathrm{P}_{2} \mathrm{~S}_{7}{ }^{4-}$ & $\mathrm{P}_{2} \mathrm{~S}_{7}{ }^{4-}$ & $\mathrm{P}_{2} \mathrm{~S}_{7}^{4-}$ & $\mathrm{PS}_{4}{ }^{3-}$ & $\mathrm{P}_{2} \mathrm{~S}_{7}^{4-}$ & $\mathrm{P}_{2} \mathrm{~S}_{7}^{4-}$ & $\mathrm{PS}_{4}{ }^{3-}$ & $\mathrm{P}_{2} \mathrm{~S}_{7}{ }^{4-}$ & $\mathrm{P}_{2} \mathrm{~S}_{7}^{4-}$ & $\mathrm{PS}_{4}{ }^{3-}$ \\
\hline$\delta_{\text {iso }}$ & 92.4 & 94.1 & 102.1 & 90.9 & 92.2 & 99.6 & 100.3 & 101.2 & 101.7 & 102.9 & 91.8 & 101.2 & 103.0 \\
\hline$\Delta^{\mathrm{a}}$ & 43 & -17 & -41 & 44 & 47 & -52 & -25 & -49 & -30 & -22 & 43.3 & -51.7 & -14.7 \\
\hline${ }^{109} \mathrm{Ag}(\mathrm{ppm})$ & \multicolumn{3}{|c|}{$\alpha$-phase (78 K) } & \multicolumn{7}{|c|}{$\beta$-phase (163 K) } & \multicolumn{3}{|c|}{$\gamma$-phase $(296 \mathrm{~K})$} \\
\hline$\delta_{\text {iso }}$ & 883 & 1039 & 1078 & 966 & & & & & & & 949 & & \\
\hline
\end{tabular}

a The following definitions are used: $\delta_{\text {iso }}=1 / 3\left(\delta_{11}+\delta_{22}+\delta_{33}\right), \Delta=\delta_{33}-\delta_{\text {iso }},\left|\delta_{33}-\delta_{\text {iso }}\right|>\left|\delta_{11}-\delta_{\text {iso }}\right|>\left|\delta_{22}-\delta_{\text {iso }}\right|$.
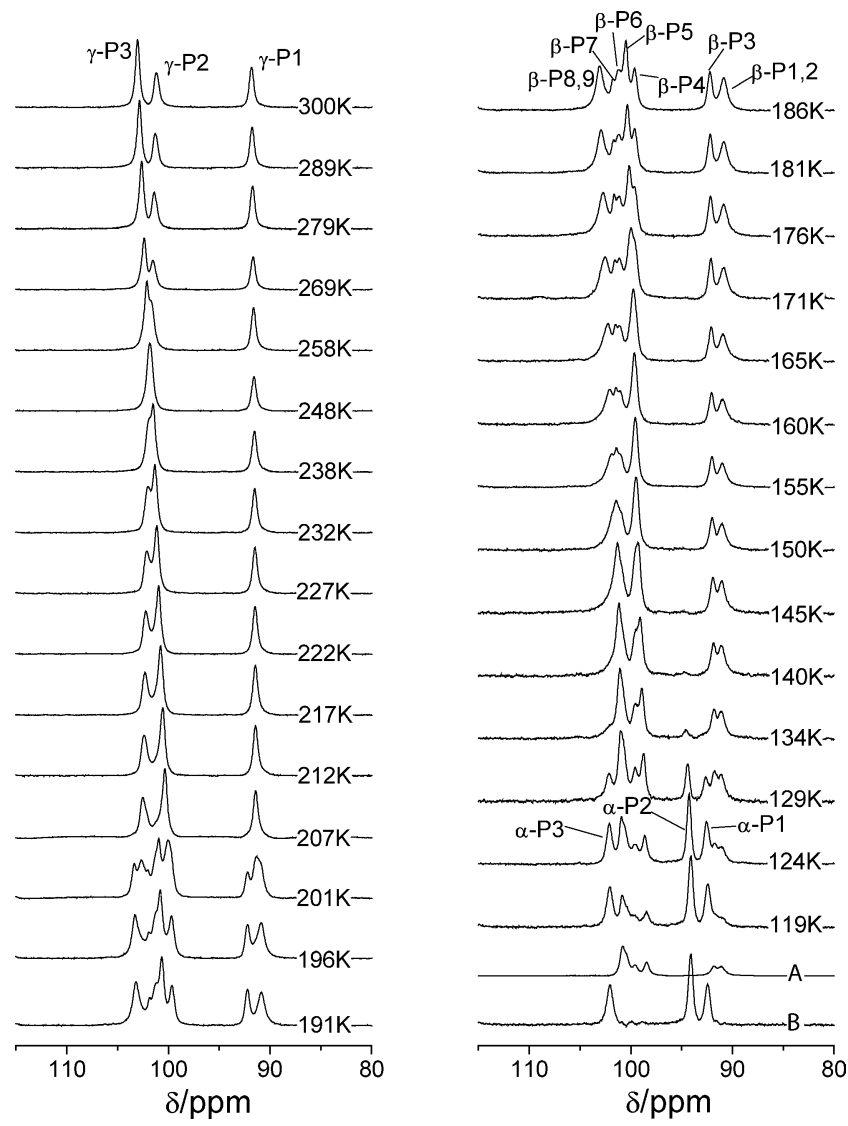

Fig. 8. Temperature dependent ${ }^{31} \mathrm{P}$ MAS NMR spectra of $\mathrm{Ag}_{7} \mathrm{P}_{3} \mathrm{~S}_{11}$, recorded at a rotor frequency of $4000 \mathrm{~Hz}$. The spectra below $140 \mathrm{~K}$ are superpositions of the peaks arising from the $\beta$-phase (trace A) and the $\alpha$-phase (trace B).

shift anisotropy of this more symmetric phosphorus site is found to be substantially smaller (around $20 \mathrm{ppm}$ ) than that associated with the $\mathrm{P}_{2} \mathrm{~S}_{7}{ }^{4-}$ units (40-50 ppm, see Fig. 9 and Table 6).

At the $\gamma \rightarrow \beta$ phase transition temperature, the number of observable signal components increases from three to nine, reflecting a change in symmetry of the thiophosphate framework. The 2D INADEQUATE spectrum obtained at $T \sim 145 \mathrm{~K}$ (Fig. 10) indicates that $\beta-\mathrm{Ag}_{7} \mathrm{P}_{3} \mathrm{~S}_{11}$ contains at least three crystallographically inequivalent $\mathrm{P}_{2} \mathrm{~S}_{7}{ }^{4-}$ groups. For each of them, the phosphorus atoms involved are crystallographically inequivalent and can be correlated with each other through their indirect dipole-dipole (scalar) couplings.

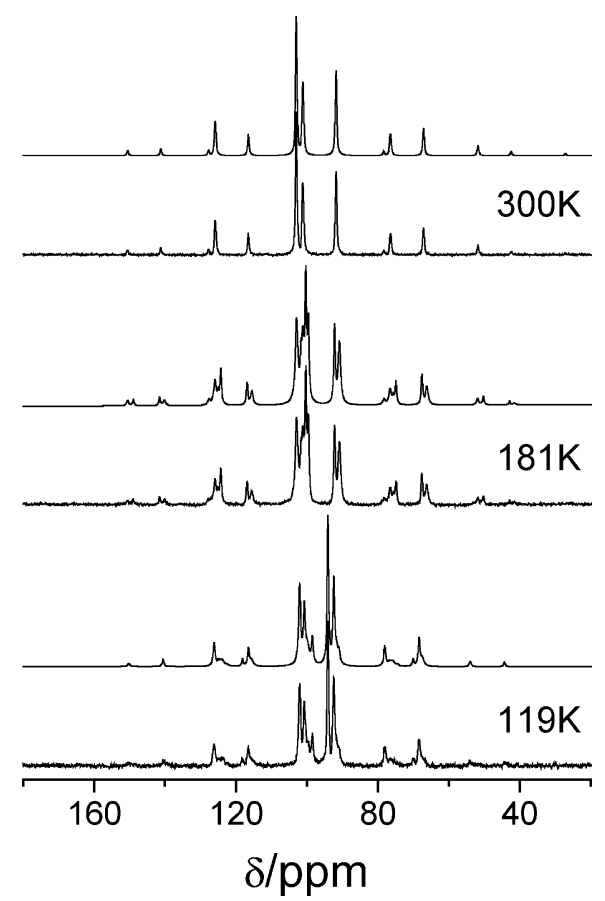

Fig. 9. $162 \mathrm{MHz}{ }^{31} \mathrm{P}$ MAS-NMR spectra of $\mathrm{Ag}_{7} \mathrm{P}_{3} \mathrm{~S}_{11}$ obtained at spinning frequencies of $4000 \mathrm{~Hz}$ at three selected temperatures. From top to bottom: $T=300 \mathrm{~K}$ ( $\gamma$-phase $), T=181 \mathrm{~K}(\beta$-phase $), T=119 \mathrm{~K}(\alpha$-phase $)$. In each part, the bottom trace represents the experimental data, the top trace the simulation, using the program DMFIT [10].

Based on the enhanced resolution of the two-dimensional spectrum, the complete one-dimensional spectrum can be deconvoluted into nine components, the proposed assignments of which are summarized in Table 6. Finally, at temperatures below $134 \mathrm{~K}$, three new resonance lines at 102.5 , 94.8 and $93.9 \mathrm{ppm}$ appear. We assign these three new resonances to the $\alpha$-phase, based on the observation that their intensities increase at the expense of the resonances from the $\beta$-phase, as the temperature is decreased. Some residual signal intensity from the $\beta$-phase remains, however, even at the lowest accessible temperatures. It is conceivable that both phases exist in an equilibrium within this temperature range, and that this equilibrium shifts with temperature. We cannot exclude the alternative possibility that this effect simply reflects substantial temperature gradients present in the NMR probe, but the effect was found to occur on both spectrometers used in the present study. The ${ }^{31} \mathrm{P}$ MAS-NMR spectrum of the pure $\alpha$-phase which was obtained by subtracting the 


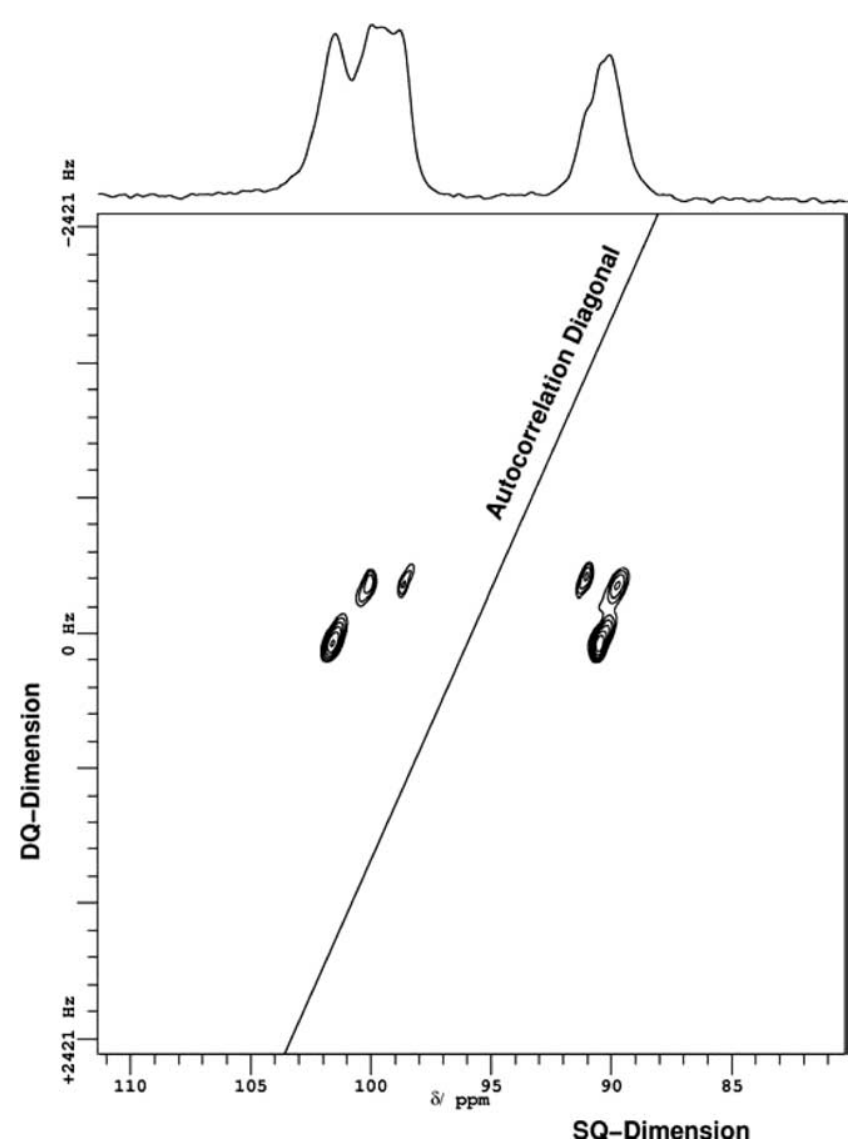

Fig. 10. $161 \mathrm{MHz}{ }^{31} \mathrm{P}$ MAS-2D-INADEQUATE spectrum of $\beta-\mathrm{Ag}_{7} \mathrm{P}_{3} \mathrm{~S}_{11}$ at $T \sim 145 \mathrm{~K}$.

$129 \mathrm{~K}$ spectrum from the $119 \mathrm{~K}$ spectrum (trace B in Fig. 8) reveals that the structure of this material contains (as the $\gamma$ phase does) only single crystallographically unique $\mathrm{PS}_{4}{ }^{3-}$ and $\mathrm{P}_{2} \mathrm{~S}_{7}{ }^{4-}$ groups each, in agreement with the single crystal X-ray diffraction result.

Fig. 11 tracks the ${ }^{31} \mathrm{P}$ chemical shifts of all the distinct resonances observed in the one-dimensional spectra as a function of temperature. As expected for phase transformations, discontinuous chemical shift changes are observed at the respective transition temperatures. Furthermore, for each phase, the chemical shift temperature coefficients measured for the $\mathrm{PS}_{4}{ }^{3-}$ groups are significantly larger compared to those measured for the $\mathrm{P}_{2} \mathrm{~S}_{7}{ }^{4-}$ units.

Aside from the number of crystallographically inequivalent $\mathrm{P}$ atoms, the ${ }^{31} \mathrm{P}$ NMR spectra give several other indications that the $\alpha$ - and the $\gamma$-phases have thiophosphate network structures that are closely related to each other. For both phases the chemical shift anisotropies associated with the $\mathrm{PS}_{4}{ }^{3-}$ groups are virtually identical and differ significantly from those measured in the $\beta$-phase (Table 6). Overall, the solid state NMR data are consistent with the re-entrant phase behavior suggested by the diffraction and Raman results. As far as the thiophosphate framework is concerned, they suggest that - most unusually - the $\beta$ - $\rightarrow \alpha$-phase transition restores the high symmetry of the $\gamma$-phase.

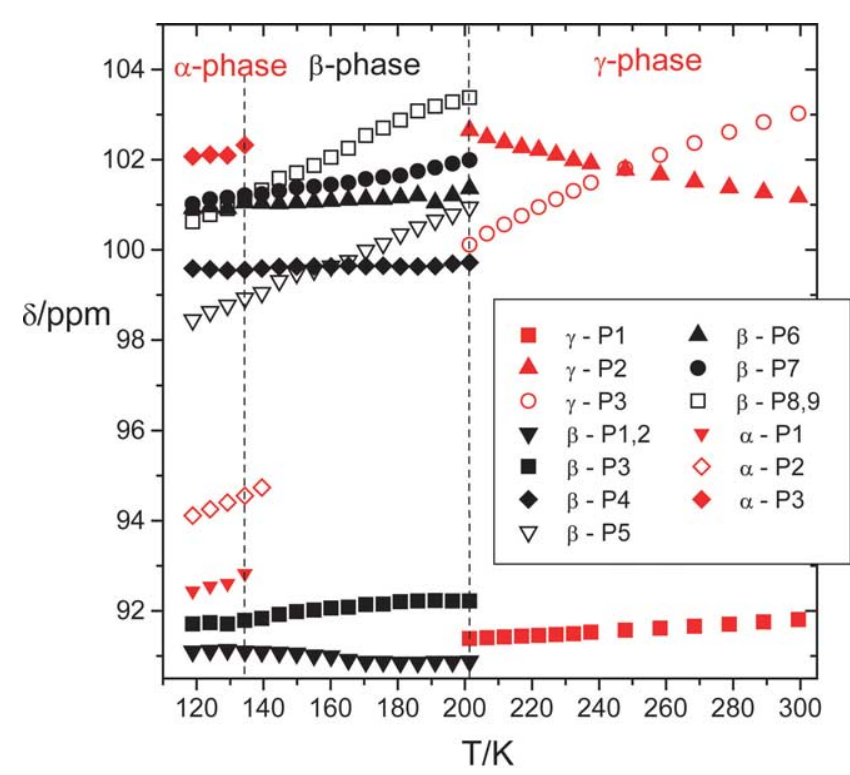

Fig. 11. Temperature dependence of the ${ }^{31} \mathrm{P}$ isotropic chemical shifts in $\mathrm{Ag}_{7} \mathrm{P}_{3} \mathrm{~S}_{11}$. Vertical lines indicate the phase transition temperatures. Open symbols: $\mathrm{PS}_{4}{ }^{3-}$ resonances; closed symbols: $\mathrm{P}_{2} \mathrm{~S}_{7}{ }^{4-}$ resonances. Signals of the $\beta$-phase are still observable below the $\beta$-to- $\alpha$ phase transition temperature.

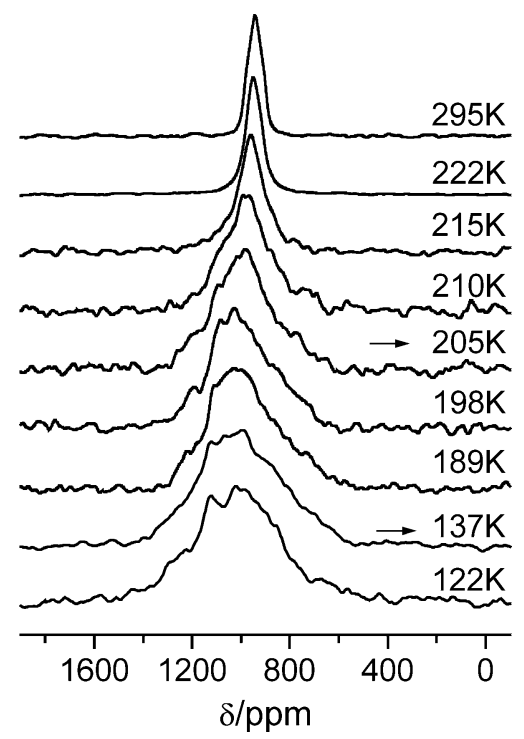

Fig. 12. Temperature dependent static ${ }^{109} \mathrm{Ag}$ NMR spectra of $\mathrm{Ag}_{7} \mathrm{P}_{3} \mathrm{~S}_{11}$, measured at $23.3 \mathrm{MHz}$.

\section{5. ${ }^{109} \mathrm{Ag}$ NMR lineshape and spin-lattice relaxation}

Figs. 12 and 13 show temperature dependent ${ }^{109} \mathrm{Ag}$ NMR spectra of $\mathrm{Ag}_{7} \mathrm{P}_{3} \mathrm{~S}_{11}$ both under static and MAS conditions. Substantial narrowing of the static lineshape is observed only in the $\gamma$-phase at temperatures above $215 \mathrm{~K}$, indicating rapid isotropic silver ionic motion on the relevant NMR timescale $\left(10^{-4} \mathrm{~s}\right)$. When the temperature is decreased the Ag NMR spectrum broadens gradually until the $\beta$-phase is reached indicating a continuous slowing down of silver ionic diffusion. Over the temperature region of stability of 


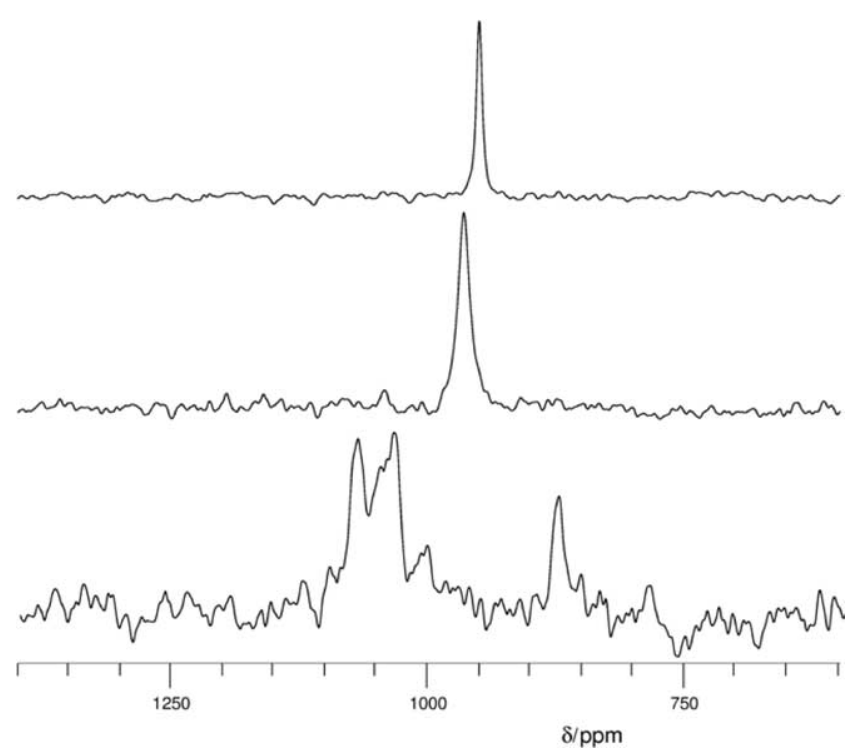

Fig. 13. Temperature dependent ${ }^{109} \mathrm{Ag}$ MAS-NMR spectra of $\operatorname{Ag}_{7} \mathrm{P}_{3} \mathrm{~S}_{11}$, measured at $18.6 \mathrm{MHz}$. From top to bottom: $\gamma$-phase at $300 \mathrm{~K}, \beta$-phase at $163 \mathrm{~K}$ (read-out temperature), $\alpha$-phase at $78 \mathrm{~K}$ (read-out temperature).

the $\beta$-phase, previously published stimulated echo measurements show that silver jumps in the $\beta$-phase occur on the $10^{-3}$ to $10^{0} \mathrm{~s}$ timescale where the temperature dependence can be described by an Arrhenius law with an activation energy $E_{\mathrm{a}}=0.37 \mathrm{eV}$ [27]. The highly nonexponential decay of the two-time correlation function results from strong dynamical heterogeneities [28]. Thus, silver diffusion in the $\beta$-phase is too slow to affect the linewidth, resulting in nearly temperature independent static spectra; only a very gradual change in overall line width is observed, which may suggest the presence of some local silver dynamics. Complementary information is revealed by the temperature dependent MAS-NMR spectra. When the exchange between the silver sites is rapid on the relevant NMR timescale, corresponding to the inverse difference in resonance frequencies $\left(10^{-1}\right.$ to $10^{-2} \mathrm{~s}$ ) motional averaging is expected. Indeed one averaged spectrum is seen in the $\gamma$-phase and in the $\beta$-phase at sufficiently high temperatures. Within each phase the motionally averaged ${ }^{109} \mathrm{Ag}$ chemical shifts are nearly temperatureindependent, however, a significant shift difference is seen between the $\gamma$-and the $\beta$-phase. Numerous discrete MAS resonances are observed in the $\alpha$-phase, suggesting that the silver ions are here immobile on the NMR timescale. At present it is not possible to assign the three resolved peaks to the seven crystallographic silver positions. The wide range of ${ }^{109} \mathrm{Ag}$ chemical shifts reveals substantial differences in the local environments in the silver sites. Ag-1 and Ag-6 are three-coordinated with sulfur, while the other silver sites are four-coordinated with various degrees of distortions. Based on these differences, it is conceivable that the peak intensity ratios observed in Fig. 13 are influenced by differences in the chemical shift anisotropies, leading to different partitions of signal intensities into MAS centerbands and spinning sidebands. Unfortunately, the low signal to noise ratio resulting

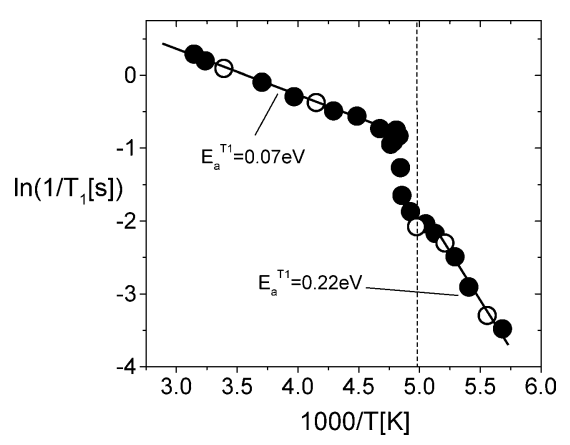

Fig. 14. Temperature dependence of the ${ }^{109} \mathrm{Ag}$ spin-lattice relaxation rates, measured in the $\beta$ - and the $\gamma$-phase. Filled and open circles represent data taken on the ${ }^{109} \mathrm{Ag}$ enriched sample and a sample with natural isotopic composition, respectively. Vertical line indicates the $\beta$ - to $\gamma$-phase transition temperature.

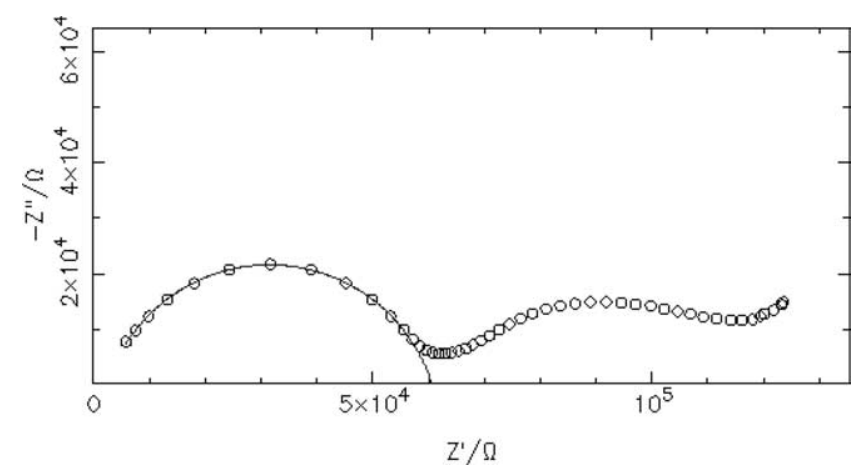

Fig. 15. Complex plane impedance plot of $\mathrm{Ag}_{7} \mathrm{P}_{3} \mathrm{~S}_{11}$ at $293 \mathrm{~K}$ as a function of frequency, indicating the extrapolation to the dc value.

from the unfavorable relaxation characteristics makes it impossible to characterize the chemical shift tensors on the basis of spinning sideband intensities.

Fig. 14 summarizes the ${ }^{109} \mathrm{Ag}$ spin lattice relaxation rates as a function of inverse temperature. No reliable data could be taken in the $\alpha$-phase, owing to extremely slow relaxation. For both the $\beta$ - and the $\gamma$-phases, however, the relaxation rates increase with increasing temperature, revealing that the slow-motion regime $\omega \tau_{c} \gg 1$ applies within the temperature range studied. The $\gamma$ - to $\beta$-phase transition manifests itself in a roughly 10 -fold decrease in the spin-lattice relaxation rate, which appears spread out over a temperature interval of about $20 \mathrm{~K}$. In addition, a distinct slope change in the $\ln T_{1}^{-1}$ versus $1 / T$ plot suggests a significant change in the value of the apparent activation energy. In spite of the clear signature of this phase transition in the spin-lattice relaxation data, these results support the previous conclusion from the temperature dependent lineshapes, that the $\mathrm{Ag}^{+}$ion dynamics change gradually rather than abruptly during the course of this phase transition and that even in the $\gamma$-phase the extreme narrowing limit is far from being approached.

\subsection{Electrical conductivity}

Fig. 15 shows a typical result from the complex impedance measurement as a function of frequency. Two semi- 


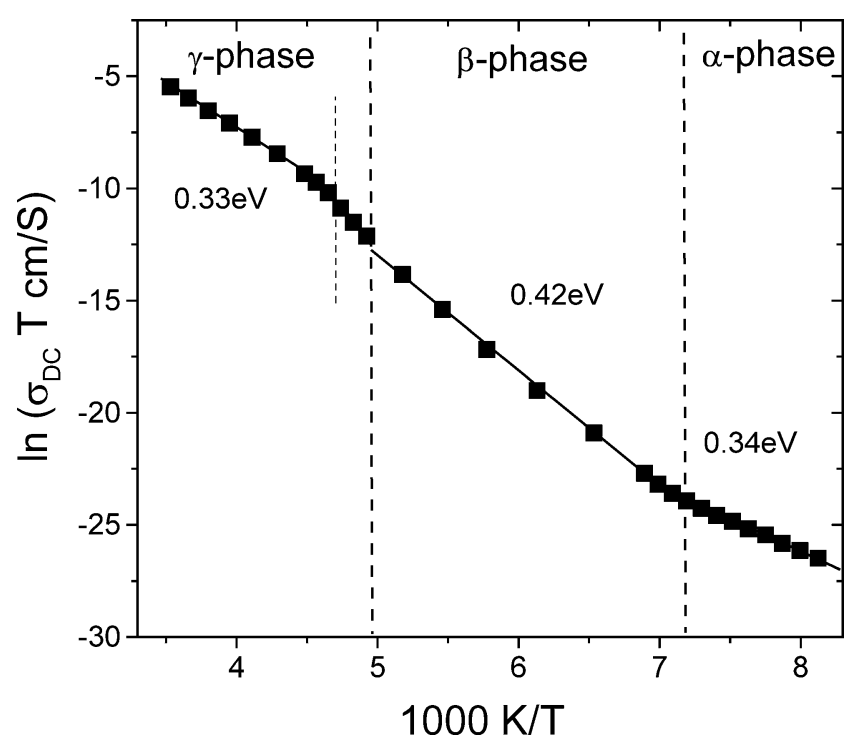

Fig. 16. Temperature dependence of the dc conductivity in $\operatorname{Ag}_{7} \mathrm{P}_{3} \mathrm{~S}_{11}$ including fits to an Arrhenius law (solid lines). For the $\gamma$-phase, only those data recorded at temperatures exceeding the one represented by the dotted line were included in the fit. Vertical dashed lines indicate the phase transition temperatures.

circles are observed, corresponding to contributions from the bulk and grain boundary effects, respectively. The bulk dc conductivity was extracted by extrapolating the first semicircle to the real axis. Temperature dependent studies (Fig. 16) reveal Arrhenius-type behavior, yielding an activation energy of $0.33 \mathrm{eV}$ for the $\gamma$-phase, in agreement with previous measurements [29]. While the absolute values of the electrical conductivities change only gradually at the respective phase transition temperatures, the activation energy increases to $0.42 \mathrm{eV}$ in the $\beta$-phase and subsequently decreases again to $0.34 \mathrm{eV}$ in the $\alpha$-phase. The latter value is nearly identical to that of the $\gamma$-phase, qualitatively supporting the idea of a re-entrant phase behavior. For the $\beta$ phase the activation energy of $0.42 \mathrm{eV}$ can be compared with $E_{\mathrm{a}}=0.37 \mathrm{eV}$ as determined from stimulated echo experiments [27].

\section{Discussion and conclusions}

As documented by various recent examples, ion localization in crystalline silver or copper ion conductors upon cooling can occur under space group conservation [18,19], symmetry reduction [30] or even symmetry increase [31]. In contrast, the silver ion conductor $\mathrm{Ag}_{7} \mathrm{P}_{3} \mathrm{~S}_{11}$ reveals a rare case of re-entrant phase behavior: Upon cooling, the hightemperature $\gamma$-phase transforms reversibly near $204 \mathrm{~K}$ to a polymorph with an unknown space group, but is restored reversibly in a more ordered form at lower temperature (130 $135 \mathrm{~K})$. The integrity of the $\mathrm{PS}_{4}{ }^{3-}$ and $\mathrm{P}_{2} \mathrm{~S}_{7}{ }^{4-}$ groups is preserved during the course of these phase transitions, whereas the $\mathrm{Ag}^{+}$ions are increasingly immobilized.
Re-entrant phase transitions of this kind are extremely rare. A particularly well-documented example from the literature is Rochelle salt, $\mathrm{NaKC}_{4} \mathrm{H}_{4} \mathrm{O}_{6} \cdot 4 \mathrm{H}_{2} \mathrm{O}$, which crystallizes in the space group $P 2{ }_{1} 2{ }_{1} 2$ above $297 \mathrm{~K}$ and below $255 \mathrm{~K}$, but exists in a distorted ferroelectric intermediate phase (space group $P 2{ }_{1} 11$ ) within this temperature interval [4]. The re-entrant phase behavior of this compound is clearly reflected in temperature dependent heat capacity [5] and single crystal ${ }^{23} \mathrm{Na}$ NMR measurements [32,33].

In view of the abrupt changes observed in the ${ }^{31} \mathrm{P}$ NMR data it may seem curious that the Raman spectra, the ${ }^{109} \mathrm{Ag}$ lineshapes and relaxation times as well as the electrical conductivities reveal smooth rather than abrupt changes at the respective phase transition temperatures. In the case of the $\beta$ - to $\alpha$-transition the ${ }^{31} \mathrm{P}$ MAS-NMR data showing the coexistence of both phases over a $10 \mathrm{~K}$ temperature range may provide the appropriate explanation in terms of a kinetically inhibited phase transition or possibly in terms of an equilibrium shifting with temperature. For the $\gamma$ - to $\beta$-phase transition, however, the explanation is more difficult. One might expect the formation of a strained intermediate between the disordered $\gamma$-phase and the completely ordered $\alpha$-phase. This strain might arise from a slowly disappearing complex rotational disorder of the constituent $\mathrm{PS}_{4}{ }^{3-}$. and $\mathrm{P}_{2} \mathrm{~S}_{7}{ }^{4-}$-groups combined with the localization of silver. The potential role of anionic reorientations in triggering such phase transitions has been discussed for a number of ionically conducting rotor phases [34]. For $\mathrm{Na}_{3} \mathrm{PO}_{4}$ such motions have recently been characterized in detail using temperature dependent ${ }^{17} \mathrm{O}$ NMR lineshape analysis [35]. Unfortunately, an analogous study of the present compound is precluded by the highly unfavorable NMR properties of the ${ }^{33} \mathrm{~S}$ isotope. The determination of the crystal structure of the $\beta$-phase is still in progress.

Detailed inspection of both the conductivity data and the ${ }^{109} \mathrm{Ag}$ relaxation rates reveal that near the low-temperature phase boundary of the $\gamma$-phase there is a narrow temperature interval $(225>T>205 \mathrm{~K})$ where the silver ion dynamics slow down more rapidly than predicted by the Arrhenius law. This trend coincides with the rather gradual change in the Raman scattering wave number associated with the $\mathrm{PS}_{4}{ }^{3-}$ mode. At the same time, we note that the ${ }^{31} \mathrm{P}$ chemical shift attributed to the $\mathrm{PS}_{4}{ }^{3-}$ unit is found strongly temperature dependent over the entire range measured, whereas no such temperature dependence can be observed for the $\mathrm{P}_{2} \mathrm{~S}_{7}{ }^{4-}$ resonances. We suggest that this effect is closely linked to the reorientational motion of the $\mathrm{PS}_{4}{ }^{3-}$ tetrahedra. As the temperature is decreased, this motion is gradually slowed down (and possibly arrested or significantly modified) near the phase transition, producing significant changes in the interactions with the $\mathrm{Ag}^{+}$ions before the new structural arrangement of the $\beta$-phase is "locked in". Thus we conclude that the gradual changes affecting the $\mathrm{Ag}^{+} / \mathrm{PS}_{4}{ }^{3-}$ local interactions make the first-order character of the $\gamma$ - to $\beta$-phase transition less evident in those observables that are sensitive to silver ion dynamics compared to those observables 
reflecting the structural features of the thiophosphate anions. To provide further support of the above hypothesis, independent evidence about the $\mathrm{PS}_{4}{ }^{3-}$ reorientational dynamics is needed by complementary techniques such as inelastic neutron scattering. Such studies might also be able to clarify the role of such anionic motions in facilitating the re-entrant phase behavior seen in the present material.

\section{Supplementary material}

Further details of the crystal structure investigations are available from the Fachinformationszentrum Karlsruhe, 76344 Eggenstein-Leopoldshafen (Germany), Fax: 0049 7247808 666, e-mail: crysdata@fiz-karlsruhe.de, on quoting the depository number CSD-414336 (298 K), and CSD$414335(120 \mathrm{~K})$, respectively, the name of the authors, and the reference of the publication.

\section{Acknowledgements}

This work was supported by the Deutsche Forschungsgemeinschaft, via the Sonderforschungsbereich SFB 458 "Ionic motion in materials with disordered structures: from elementary jumps to macroscopic transport". We thank Professor A. Putnis for valuable discussion, Drs. M. Andratschke and T. Nilges for some help with the experiments and Ms. Wilma Pröbsting for the DSC measurements.

\section{References}

[1] P.E. Cladis, Phys. Rev. Lett. 35 (1975) 48.

[2] F. Hardouin, G. Sigaud, M.F. Achard, H. Gasparoux, Phys. Lett. A 71 (1979) 347.

[3] T. Narayanan, A. Kumar, Phys. Rep. 249 (1994) 135.

[4] C.A. Beevers, W. Hughes, Proc. R. Soc. London, Ser. A 177 (1941) 251

E. Suzuki, Y. Shiozaki, Phys. Rev. B 53 (1996) 5217.

[5] P.K. Dey, K.K. Som, K.R. Chowdhury, B.K. Sarkar, B.K. Chaudhuri, Phys. Rev. B 47 (1993) 3001.
[6] T. Wasiutynski, W. Olejarczyk, J. Sciesinski, W. Witko, J. Phys. C 20 (1987) L65.

[7] I.H. Brunskill, W. Depmeier, Acta Crystallogr. A 38 (1982) 132.

[8] P.P. Toffoli, P. Khodadad, N. Rodier, Acta Crystallogr. B 38 (1982) 2374.

[9] H. Andrae, R. Blachnik, J. Therm. Anal. 35 (1989) 595.

[10] D. Massiot, F. Fayon, M. Capron, I. King, S. Le Calve, B. Alonso, J.O. Durand, B. Bujoli, Z. Gan, G. Hoatson, Magn. Reson. Chem. 40 (2002) 70 .

[11] J. Schmedt auf der Günne, PhD thesis, Münster, 2000.

[12] D. Marion, M. Ikura, R. Tschudin, A. Bax, J. Magn. Reson. 85 (1989) 393.

[13] W.F. Hemminger, H.K. Cammenga, Methoden der Thermischen Analyse, Springer-Verlag, Berlin, 1985, p. 131.

[14] G.M. Sheldrick, SHELX 97, Programs for the solution and refinement of crystal structures, University of Göttingen, Germany, 1997.

[15] V. Petricek, M. Dusek, The crystallographic computing system JANA2000, Institute of Physics, Praha, Czech Republic, 2000.

[16] A. Pfitzner, M. Evain, V. Petricek, Acta Crystallogr. B 53 (1997) 337.

[17] A. van der Lee, F. Boucher, M. Evain, R. Brec, Z. Kristallogr. 203 (1993) 247.

[18] A. Pfitzner, Chem. Eur. J. 3 (1997) 2032.

[19] T. Nilges, S. Reiser, J.H. Hong, E. Gaudin, A. Pfitzner, Phys. Chem. Chem. Phys. 4 (2002) 5888.

[20] U. Patzmann, W. Brockner, Z. Naturforsch. 38a (1983) 27.

[21] F. Menzel, W. Brockner, M. Ystenes, J. Mol. Struct. 53-56 (1993) 294.

[22] F. Menzel, L. Ohse, W. Brockner, Heteroatom Chem. 1 (1990) 357.

[23] F.H. Ryan, K.D. Abney, J.L. Burris, H.D. Hochheimer, P.K. Dorhout, Inorg. Chem. 40.

[24] Z. Zhang, J.H. Kennedy, H. Eckert, J. Amer. Chem. Soc. 144 (1992) 5775.

[25] J. Schmedt auf der Günne, H. Eckert, Chem. Eur. J. 4 (1998) 1762.

[26] J. Schmedt auf der Günne, S. Kaczmarek, L. van Wüllen, H. Eckert, D. Paschke, A.J. Foecker, W. Jeitschko, J. Solid State Chem. 147 (1999) 341.

[27] M. Vogel, C. Brinkmann, H. Eckert, A. Heuer, J. Non-Cryst. Solids 307-310 (2002) 971.

[28] M. Vogel, C. Brinkmann, H. Eckert, A. Heuer, Phys. Rev. B 69 (2004) 094302.

[29] Z. Zhang, J.H. Kennedy, J. Electrochem. Soc. 140 (1993) 2384.

[30] T. Nilges, S. Nilges, A. Pfitzner, T. Doert, P. Böttcher, Chem. Mater. 16 (2004) 806.

[31] A. Pfitzner, Z. Kristallogr. 213 (1998) 228.

[32] T. Oja, P.A. Casabella, Phys. Rev. 177 (1969) 830.

[33] N.C. Miller, P.A. Casabella, Phys. Rev. 152 (1966) 228.

[34] M. Jansen, Angew. Chem. 103 (1991) 1574.

[35] M. Witschas, H. Eckert, H. Freiheit, A. Putnis, G. Korus, M. Jansen, J. Phys. Chem. 105 (2001) 6808. 